ARTICLE

\title{
Clearance of HIV infection by selective elimination of host cells capable of producing HIV
}

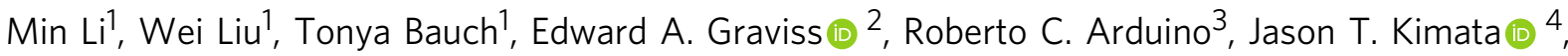 \\ Min Chen (i) ${ }^{5} \&$ Jin Wang (1) ${ }^{1,6 凶}$
}

The RNA genome of the human immunodeficiency virus (HIV) is reverse-transcribed into DNA and integrated into the host genome, resulting in latent infections that are difficult to clear. Here we show an approach to eradicate HIV infections by selective elimination of host cells harboring replication-competent HIV (SECH), which includes viral reactivation, induction of cell death, inhibition of autophagy and the blocking of new infections. Viral reactivation triggers cell death specifically in HIV-1-infected T cells, which is promoted by agents that induce apoptosis and inhibit autophagy. SECH treatments can clear HIV-1 in $>50 \%$ mice reconstituted with a human immune system, as demonstrated by the lack of viral rebound after withdrawal of treatments, and by adoptive transfer of treated lymphocytes into uninfected humanized mice. Moreover, SECH clears HIV-1 in blood samples from HIV-1-infected patients. Our results suggest a strategy to eradicate HIV infections by selectively eliminating host cells capable of producing HIV.

\footnotetext{
${ }^{1}$ Immunobiology and Transplant Science Center, Houston Methodist Research Institute, Houston, TX 77030, USA. ${ }^{2}$ Department of Pathology and Genomic Medicine, Houston Methodist Research Institute, Houston, TX 77030, USA. ${ }^{3}$ Division of Infectious Diseases, Department of Internal Medicine, McGovern Medical School at The University of Texas Health Science Center, Houston, TX 77030, USA. 4 Department of Molecular Virology and Microbiology, Baylor College of Medicine, Houston, TX 77030, USA. ${ }^{5}$ Department of Pathology and Immunology, Baylor College of Medicine, Houston, TX 77030, USA.

${ }^{6}$ Department of Surgery, Weill Cornell Medical College, Cornell University, New York, NY 10065, USA. ${ }^{凶}$ email: jinwang@houstonmethodist.org
} 
T he acquired immunodeficiency syndrome (AIDS) is caused by HIV, which infects and depletes $\mathrm{CD} 4^{+} \mathrm{T}$ cells in the patients ${ }^{1}$. The RNA genome of HIV type 1 (HIV-1) is reverse-transcribed into DNA and integrated into the host genome, resulting in persistent infections that are difficult to eradicate $^{2}$. Combination antiretroviral therapy (cART) targeting different stages of the HIV-1 replication cycle can effectively inhibit viral replication and prevent the onset of AIDS $^{3}$. The seeding of refractory latent viral reservoir takes place rapidly in human HIV-1 patients and in Simian immunodeficiency virus (SIV)-infected rhesus monkeys ${ }^{4,5}$. A stable HIV-1 proviral reservoir persists during $\mathrm{cART}^{6-8}$. Continuous cART is necessary to prevent new virus production from the HIV-1 reservoir? Interestingly, two leukemia patients infected with HIV-1 have been reported to be cured of the virus through regimens of total body irradiation or chemotherapy plus antibody-mediated depletion of lymphocytes, followed by transplantation of hematopoietic stem cells from homozygous CCR5 32 donors ${ }^{10,11}$. However, a cure strategy for HIV-1 infections that is practical for people living with HIV in the general population remains to be developed.

HIV-1 has evolved mechanisms to evade immune recognition. Inducing the expression of HIV-1 with latency reversal agents (LRAs) to display viral antigens may trigger immune responses against latently infected cells ${ }^{12}$. However, LRAs alone have not been shown to reduce or clear HIV infections ${ }^{13}$, suggesting the requirement for additional approaches. Using a long-acting antiviral therapy and adenovirus-mediated delivery of CRISPRCas9 to excise integrated HIV-1, it was shown that HIV-1 was cleared from two human cell-implanted mice ${ }^{14}$. It has been shown that only a small portion $(<3 \%)$ of integrated HIV-1 is capable of producing the infectious virions, whereas most integrated proviruses are defective and pose no risks in producing the virus ${ }^{15}$. Thus, the majority of the infected cells, which are nonproductively infected, do not need to be cleared to achieve a cure for HIV-1. So far, the task of finding the needle in a haystack to sort out and destroy the HIV-1 reservoir capable of producing the virus has been challenging.

Killing cells harboring intact HIV-1 proviruses would be ideal for clearing the HIV-1 reservoir. HIV-1 can trigger different cell death pathways in $\mathrm{T}$ cells ${ }^{16-23}$. Interestingly, productive HIV-1 infection induces caspase-dependent apoptosis in host cells, whereas abortive HIV-1 infection leads to pyroptosis ${ }^{24}$. We and others have found that cell types important for immunological memory, including memory $\mathrm{B}$ cells, and $\mathrm{CD}^{+}$, and $\mathrm{CD}^{+}$ memory $\mathrm{T}$ cells, depend on autophagy for their long-term survival ${ }^{25-28}$. Because $\mathrm{CD} 4{ }^{+}$memory $\mathrm{T}$ cells are the major reservoir for latent HIV-1, we hypothesize that targeting autophagy would facilitate the elimination of latent HIV-1 infection. By a selective elimination of host cells harboring replication-competent HIV (SECH) approach with the combination of latency reversal, inhibition of autophagy and induction of apoptosis, we show that it is feasible to clear host cells harboring replication-competent HIV-1 in humanized mice in vivo, as well as in blood samples from HIV-1-infected patients in vitro.

\section{Results}

Inhibition of autophagy promotes host cell apoptosis. As autophagy is important for the protection of memory T cells, we tested whether inhibition of autophagy can help to reduce the HIV-1 reservoir in these cells. We used $\mathrm{CD}^{+}{ }^{+} \mathrm{CD} 4{ }^{+} \mathrm{CD} 45 \mathrm{RO}$ ${ }^{+} \mathrm{CCR}^{+}$central memory T cells (CMT; Supplementary Fig. 1a) for HIV-1 infection and culture in the presence of CCL19 to establish HIV latent infection ${ }^{29}$. Four days after infection with CXCR4-tropic HIV-1 NL4- $3^{30}$ at 0.1 multiplicity of infection
(MOI), CMT showed no detectable expression of HIV-1 p24 protein (Fig. 1a, Supplementary Fig. 1b). Stimulation with phytohemagglutinin (PHA) led to latency reversal of HIV-1 as shown by the induction of p24 (Fig. 1a, Supplementary Fig. 1b). Latency reversal was also observed by the expression of HIV-1 mRNA after stimulation with PHA or ingenol-3,20-dibenzoate (IDB), a non-tumorigenic protein kinase $c-\varepsilon$ activator $^{31}$ (Supplementary Fig. 1c). Interestingly, inhibition of autophagy in $\mathrm{T}$ cells by silencing the expression of an essential autophagy gene, $\operatorname{Atg} 7^{32}$, reduced the number of HIV-1 $24^{+}$cells after PHA stimulation (Fig. 1a). Consistently, SAR405, an autophagy inhibitor that prevents autophagy initiation by suppressing VPS34 ${ }^{33}$, decreased the number of HIV-1 p24-producing T cells after latency reversal (Fig. 1b, Supplementary Fig. 2a). Chloroquine (CQ), another autophagy inhibitor that blocks the progression of autophagolysomes $^{34}$, also reduced the number of HIV-1 p24-producing T cells after latency reversal (Fig. 1b). We also established HIV latency in CMT infected with CCR5-utilizing HIV-1 AD8 ${ }^{35}$ at 1 MOI, and induced latency reversal with IDB (Supplementary Fig. 1c). Induction of HIV-1 p24 expression by IDB-induced latency reversal was also inhibited by SAR405 (Supplementary Fig. 2b). These data suggest that inhibition of autophagy can reduce the numbers of cells capable of producing HIV-1.

Inhibition of autophagy may reduce HIV-1 p24 ${ }^{+}$cells after latency reversal by affecting HIV-1 reverse transcription, integration of viral DNA into the host genome, viral reactivation or host cell survival. To distinguish between these possibilities, we measured early and late products of reverse transcription by $R / U 5$ and LTR-gag reverse transcription polymerase chain reaction (RT-PCR), respectively ${ }^{36}$. We observed that the production of early and late HIV-1 transcripts, which indicates the level of reverse transcription, was not affected by silencing of Atg7 or treatment with SAR405 (Fig. 1c, d). We also found that inhibition of autophagy did not affect HIV-1 integration into the host genome by Alu-gag PCR ${ }^{37}$ (Fig. 1e). Induction of HIV-1 mRNA expression from latently infected cells was also unaffected by inhibition of autophagy (Fig. 1f). Moreover, induction of HIV-1 mRNA in latently infected peripheral blood mononuclear cells (PBMCs) from ART-treated HIV-1 patients was not changed by SAR405 (Fig. 1g), indicating that autophagy is not required for the reactivation of latently infected HIV-1. Together, these data suggest that inhibition of autophagy does not have a direct effect on reverse transcription, integration, and reactivation of latent HIV-1.

Interestingly, we observed that latency reversal with IDBinduced cell death in HIV-1-infected CMT, as shown by annexin $\mathrm{V}$ staining (Fig. 1h), and increased caspase- 3 activities measured by cleavage of DEVD (Fig. 1i). Moreover, IDB-induced cell death in HIV-1-infected CMT was promoted by autophagy inhibitors SAR405 and CQ (Fig. 1h, i). These data suggest that inhibition of autophagy promotes host cell death during latency reversal.

Specific killing of host cells by HIV-1 reactivation. We found that IDB-mediated latency reversal induced the activation of caspase-9, caspase-3, caspase-6, and caspase-7 in HIV-1-infected $\mathrm{T}$ cells, as shown by the appearance of active processed forms of these caspases (Fig. 2a). This is consistent with the possibility that latency reversal by IDB induces cell death in HIV-1-infected host cells (Fig. 1h, i). Treatment with IDB did not change the expression of antiapoptotic Bcl-2, but increased the expression of antiapoptotic Bcl-xL and Mcl-1 in $\mathrm{CD} 4^{+} \mathrm{T}$ cells with or without HIV-1 infections (Fig. 2a). The increase in Bcl-xL expression in HIV-1-infected cells was greater than in uninfected controls (Fig. 2a). This indicates that HIV replication may synergize with IDB in inducing antiapoptotic Bcl-xL, reminiscent of the roles for 
a

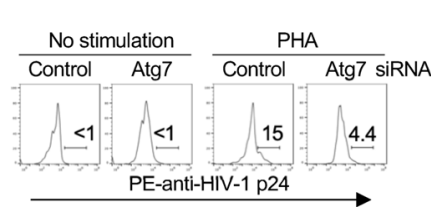

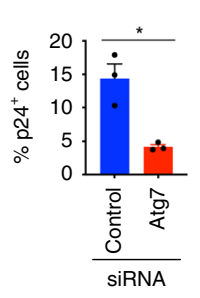

b
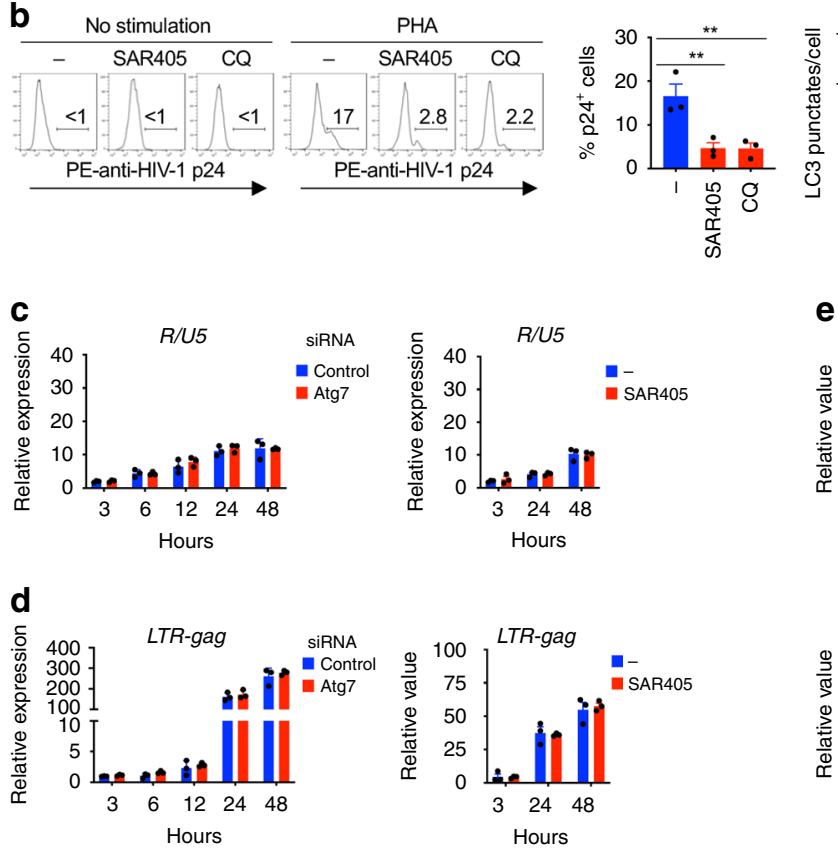

e

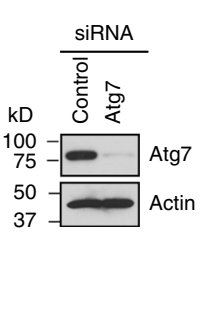

f
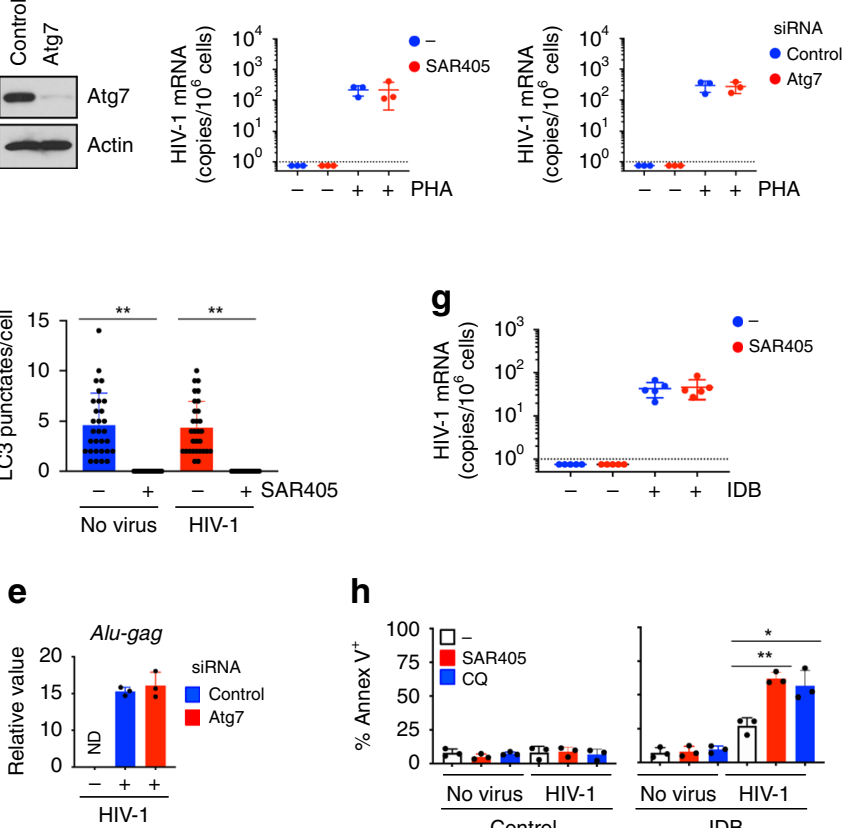

h

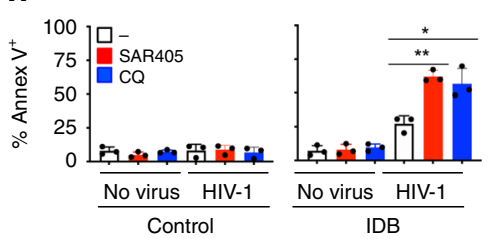

i

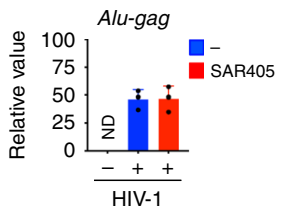

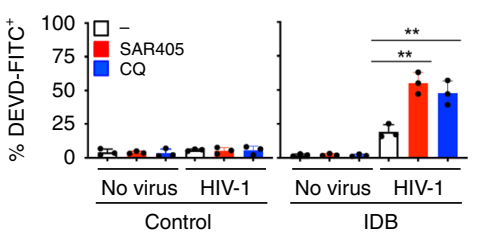

Fig. 1 Regulation of host cell survival, but not HIV-1 reverse transcription and integration into the host genome by inhibition of autophagy. a CMT transfected with Atg7 siRNA were infected with HIV-1 (NL4-3, 0.1 MOI) and cultured for $4 \mathrm{~d}$ to establish latency. After latency reversal by PHA, p24+ cells ( $n=3$ biologically independent samples) and Atg7 expression (representative of two biologically independent experiments) were determined. ${ }^{*} p=0.011$. $\mathbf{b}$ CMT latently infected with HIV-1 were stimulated with IDB with SAR405 $(2 \mu \mathrm{M})$ or CQ $(10 \mu \mathrm{M})$. p24 staining and the number of LC3 punctate per cells were analyzed. p24+ cells ( $n=3$ biologically independent experiments), $p=0.010$ (SAR405) and 0.0098 (CQ); LC3 punctate/cell ( $n=30$ cells from two biologically independent experiments), $p=0.0001$ (no virus) and 0.0001 (HIV-1). c, d Atg7 siRNA-transfected CMT were infected with HIV-1.

Alternatively, CMT infected with HIV-1 were cultured with SAR405. Cells at different time after infection were collected ( $n=3$ biologically independent samples) for RT-PCR for R/U5 c and LTR-gag d. e Alu-gag PCR for genomic DNA from CMT as in a, CMT treated with SAR405 as in b or uninfected CMT. Data were normalized against $\beta$-globin. ND: not detectable. Data are presented as mean \pm SD $(n=3$ biologically independent samples). $\mathbf{f}, \mathbf{g}$ CMT cultured as in $\mathbf{a}$, $\mathbf{b}$ were reactivated with PHA for $24 \mathrm{~h} \mathbf{f}$ ( $n=3$ biologically independent samples). PBMCs from ART-treated HIV-1-infected patients ( $n=5$ patients) were stimulated with IDB in the presence or absence of SAR405 for $24 \mathrm{~h} \mathbf{g}$. HIV-1 mRNA was determined by RT-PCR. Data are presented as mean \pm SD. The dashed line indicates detection limit. h, i CMT latently infected with HIV-1 (NL4-3, 1 MOI) as in a were reactivated with $100 \mathrm{nM} \mathrm{IDB}$ for $24 \mathrm{~h}$. Annexin $\mathrm{V}$ $\mathbf{h}$ or DEVD $\mathbf{i}$ staining were analyzed by flow cytometry ( $n=3$ biologically independent samples). SAR405 vs. control, $p=0.0012 \mathbf{h}, 0.0024 \mathbf{i}$; CQ vs. control, $p=0.0164 \mathbf{h}, 0.0088 \mathbf{i}$. Source data are provided as a Source Data file.

viral components in the regulation of $\mathrm{Bcl}-\mathrm{xL}^{38}$. Moreover, IDB also induced the expression of LC3 in T cell with or without HIV1 infections (Fig. 2a), indicating that IDB promotes autophagy in $\mathrm{T}$ cells. Although IDB can induce virus production in $\mathrm{T}$ cells harboring latent HIV-1 to trigger apoptosis, the upregulation of antiapoptotic molecules and autophagy by IDB would counteract apoptosis signaling. This may explain in part why the use of LRAs alone is not sufficient to clear HIV-1-infected cells. Nevertheless, the induction of antiapoptotic molecules and autophagy by IDB may have the advantage by conferring resistance of uninfected $\mathrm{T}$ cells to the induction of cell death.

Killing of host cells by targeting apoptosis and autophagy. Virus reactivation by IDB-induced cell death in HIV-1-infected $\mathrm{T}$ cells as shown by staining with Annexin $\mathrm{V}$ and cleavage of DEVD, whereas uninfected cells were relatively resistant (Fig. 2b, c). Inhibition of autophagy with SAR405 increased IDB-induced killing of T cells latently infected by HIV-1 (Fig. 2b, c). Because latency reversal by IDB also showed the unintended effect of increasing antiapoptotic molecules (Fig. 2a), targeting antiapoptotic molecules in addition to reactivating the virus is potentially advantageous in promoting the killing of HIV-infected cells. Indeed, an inhibitor of Bcl-2 and Bcl-xL, ABT-26339, increased IDB-mediated cell death in latently infected T cells, as shown by staining with Annexin V and DEVD-FITC (Fig. 2b, c). ABT-263 significantly increased the loss of viable HIV-1 p24 ${ }^{+}$ cells in IDB-stimulated HIV-1-infected cells (Fig. 2d). This suggests that counteracting antiapoptotic molecules and inhibiting autophagy can promote the killing of HIV-1-infected T cells induced by latency reversal.

To eradicate HIV infections, all $\mathrm{T}$ cells that are capable of producing infectious HIV-1 need to be cleared. We found that combining SAR405 with ABT-263 and IDB further increased cell death in HIV-infected T cells (Fig. 2b, c). Moreover, over 95\% of 
a
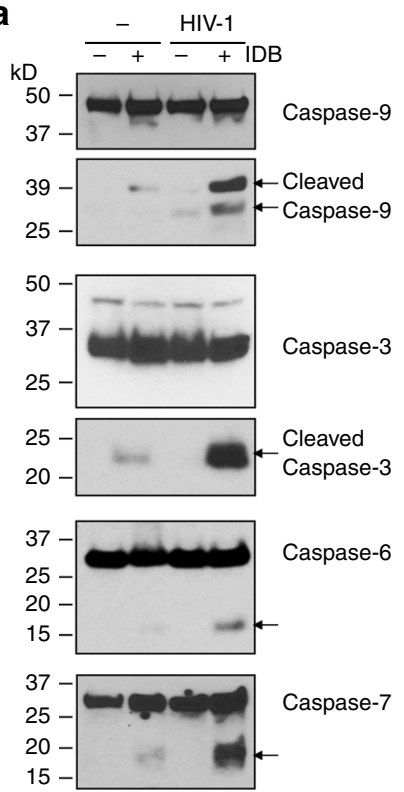

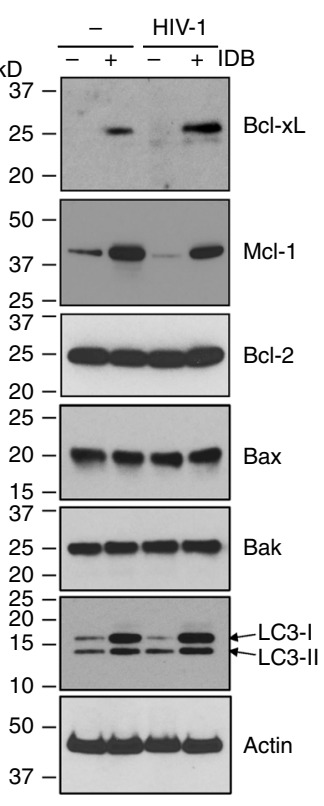

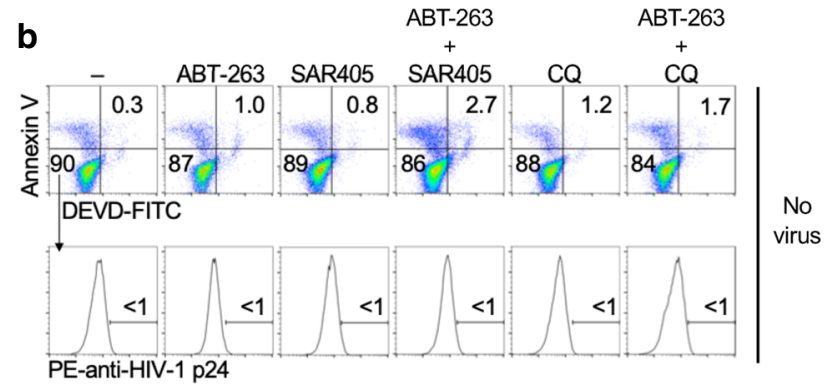

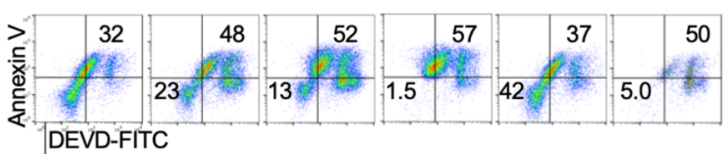

DEVD-FITC

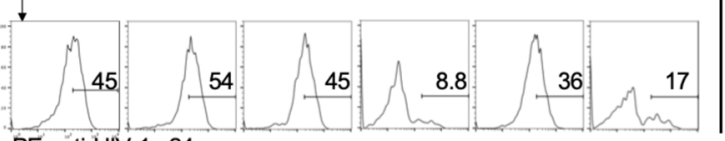

PE-anti-HIV-1 p24
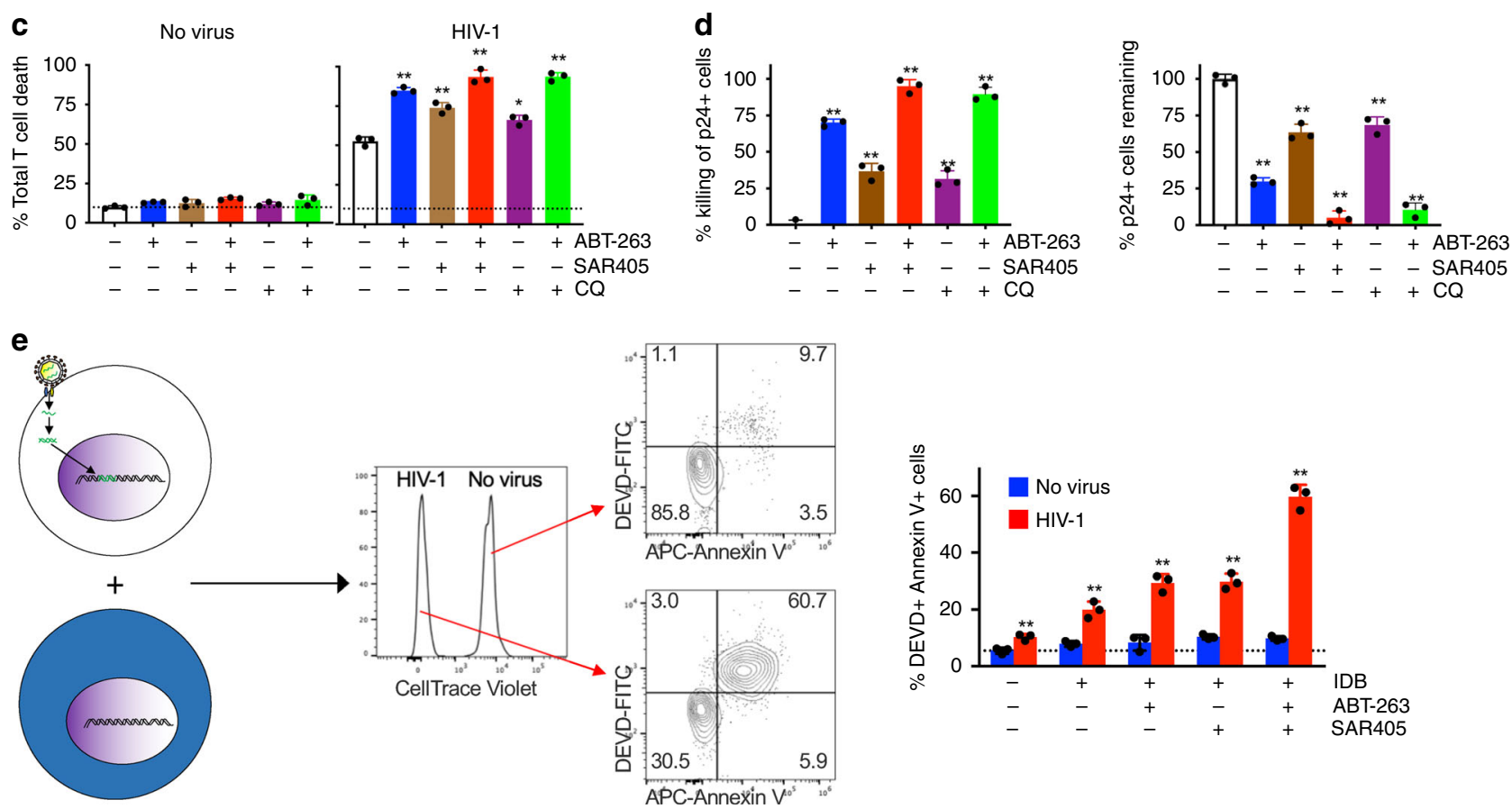

Fig. 2 Induction of caspase activation and cell death in HIV-1-infected T cells. a CD4 ${ }^{+}$T cells from PBMCs with or without infection by HIV-1 (NL4-3, 1 $\mathrm{MOI}$ ) were cultured for 4 days to establish latency, followed by stimulation with IDB for $24 \mathrm{~h}$. Cell lysates were used for western blot (representative of two biologically independent experiments). Arrows indicate cleaved caspases. b CMT with or without infection by HIV-1 (NL4-3, $1 \mathrm{MOI}$ ) were cultured for 4 days to establish latency. The cells were stimulated with $0.1 \mu \mathrm{M}$ IDB. ABT-263 (0.2 $\mu \mathrm{M})$ and SAR405 $(2 \mu \mathrm{M})$ and chloroquine $(C Q, 10 \mu \mathrm{M})$ were added as indicated. The cells were cultured for $48 \mathrm{~h}$, followed by incubation with DEVD-FITC, staining with APC-Annexin V, and intracellular staining with PE-antiHIV p24. c Total cell death for cells treated in $\mathbf{b}$ was calculated ( $n=3$ biologically independent samples). Data are presented as mean \pm SD. $p$ values for control vs. five treatment groups in sequence: $0.0001,0.0011,0.0002,0.0049$, and 0.0001 (one-way ANOVA with unpaired two-tailed $t$ test). d The combinations of ABT-263 and SAR405 or CQ in the killing of IDB-stimulated HIV-1-infected T cells in $\mathbf{b}$ was calculated. The remaining viable HIV-1 p24+ cells (negative for staining by APC-annexin V and DEVD-FITC) in $\mathbf{b}$ were also calculated. Data are presented as mean \pm SD ( $n=3$ biologically independent samples). $p$ values for control vs. four treatment groups in sequence (for killing of p24+ cells and for $p 24^{+}$cells remaining): $0.0001,0.0006,0.0001$, 0.0011 , and 0.0001 (one-way ANOVA with unpaired two-tailed $t$ test). e T cells latently infected with HIV-1 as in Fig. 1a were mixed with CellTrace violetlabeled uninfected T cells, and cultured with IDB, SAR405, and ABT-263 as in b, in the presence of $0.2 \mu \mathrm{M}$ BMS-626529 for $48 \mathrm{~h}$. The cells were stained with DEVD-FITC and APC-Annexin V, followed by flow cytometry analysis. Data are presented as mean \pm SD and are representative of five independent experiments. $p$ values for control vs. four treatment groups (HIV-1-infected samples) in sequence: 0.0059, 0.0005, 0.0004, and 0.0001 (one-way ANOVA with unpaired two-tailed $t$ test). Source data are provided as a Source Data file. 
HIV-1-p24 ${ }^{+}$cells in HIV-1-infected T cells could be killed within 2 days in vitro (Fig. 2d), whereas uninfected $\mathrm{T}$ cells were relatively resistant (Fig. 2b, c). Use of CQ instead of SAR405 also achieved similar results (Fig. $2 \mathrm{~b}-\mathrm{d}$ ). These results suggest that latency reversal in combination with inhibition of autophagy and induction of apoptosis could efficiently kill HIV-1-infected T cells.

HIV-1 can establish latency in both resting and activated $\mathrm{T}$ cells ${ }^{40}$. In addition to memory $\mathrm{T}$ cells, certain levels of autophagy are present in $\mathrm{T}$ cells at all developmental stages ${ }^{41}$. We therefore examined whether inhibition of autophagy might affect the survival of $\mathrm{HIV}$-1-infected $\mathrm{CD}^{+}{ }^{+} \mathrm{T}$ cells with different differentiation and activation status in addition to CMT, including $\mathrm{CD}^{+}{ }^{+} \mathrm{CD} 4{ }^{+} \mathrm{CD} 45 \mathrm{RO}^{+} \mathrm{CCR}^{-}$effector memory $\mathrm{T}$ cells (EMT), $\mathrm{CD}^{+}{ }^{+} \mathrm{CD} 4{ }^{+} \mathrm{CD} 45 \mathrm{RO}^{-} \mathrm{CCR}^{+}$naive $\mathrm{T}$ cells (Supplementary Fig. 1a), as well as $\mathrm{CD} 4^{+} \mathrm{T}$ cells activated with PHA and IL-2. We found that the combination of IDB-induced latency reversal with inhibition of autophagy and promotion of apoptosis could kill a majority of these T cells infected by HIV-1 but not uninfected controls (Supplementary Fig. 3a-d). These results support the conclusion that the killing of HIV-1-infected $\mathrm{T}$ cells by latency reversal in combination with inhibition of autophagy and induction of apoptosis is selective.

Specific killing of HIV-1-infected cells but not bystanders. To further determine the selectivity in the killing of HIV-1-infected cells by latency reversal with inhibition of autophagy and promotion of apoptosis, we labeled uninfected T cells with CellTrace Violet and mixed them with T cells latently infected by HIV-1 (Fig. 2e). An attachment inhibitor that targets HIV-1 gp120 and blocks its binding to CD4 ${ }^{+} \mathrm{T}$ cells, BMS-626529 ${ }^{42}$, was added to prevent new rounds of infection. Treatments with IDB, ABT-263, and SAR4505 alone or together killed HIV-1-infected cells, whereas uninfected cells were resistant (Fig. 2e). These results suggest that IDB-induced latency reversal, in combination with the inhibition of autophagy and promotion of apoptosis, leads to selective killing of HIV-1-infected cells but not the uninfected bystanders.

Virus reactivation by IDB potentially confers the specificity in the killing of HIV-1-infected cells by selectively inducing caspase activation and apoptosis (Fig. 2a). The unintended effect of up regulating antiapoptotic molecules and autophagy by IDB may be mitigated by using ABT-263 and SAR405. Inhibition of autophagy could remove an important protective mechanism for cell survival, thereby unleashing the cell death pathways in HIV-1-infected $\mathrm{T}$ cells triggered by IDB and by proapoptotic ABT-263 (Fig. 2b, c; Supplementary Fig. 3). IDB-induced upregulation of antiapoptotic molecules and the induction of autophagy in cells not infected by HIV-1 may protect these cells against cell death (Fig. 2a), thereby increasing the specificity in the killing of HIV-1-infected cells.

Clearance of HIV-1 infections in humanized mice by SECH. To determine whether it was possible to clear HIV-1 infection in vivo by killing HIV-1-infected cells, we used a humanized mouse model containing a reconstituted human immune system that had been established for HIV-1 infection and cure studies ${ }^{43}$. We designed a SECH approach for selective elimination of host cells capable of producing HIV, including the use of IDB for latency reversal, in combination with agents that induce apoptosis and inhibit autophagy to eliminate HIV-1-infected cells in humanized mice (Fig. 3a). However, IDB is expected to induce the production of new HIV-1 virions that can infect other cells. We included antiretroviral drugs that aim to inhibit the HIV-1 fusion and integration (Fig. 3a). We used a prodrug for attachment inhibitor
BMS-626529, BMS-663068, with increased solubility and can be converted to the active and cell permeable BMS-626529 by alkaline phosphatase in the intestine ${ }^{44}$, as well as raltegravir, an integrase strand transfer inhibitor that prevents viral integration $^{45}$. Other drugs commonly used in cART, such as reverse transcriptase inhibitors and protease inhibitors ${ }^{3}$, were not included. This would thus permit viral production to induce cell death signaling in infected cells while preventing virus spread, thereby protecting neighboring healthy cells from infection by newly produced HIV-1.

To generate mice implanted with human $\mathrm{CD} 34^{+}$hematopoietic stem cells (Hu-HSC mice), we used immunodeficient NSGSGM3 mice with transgenic expression of human IL-3, granulocyte macrophage-colony stimulating factor (GM-CSF), and stem cell factor that support the stable engraftment of a variety of cell types in the immune system, including both myeloid and lymphoid lineages ${ }^{46-48}$. After engraftment of human $\mathrm{CD} 34^{+}$stem cells, mice were efficiently reconstituted with human $\mathrm{CD}^{+}{ }^{+}$and $\mathrm{CD}^{+}{ }^{+} \mathrm{T}$ cells, B cells, NK cells, dendritic cells, and macrophages (Fig. 3b; Supplementary Fig. 4a; Supplementary Table 1). Hu-HSC mice used for this set of experiment were reconstituted with an average of $33 \%$ human $\mathrm{CD}^{+} 5^{+}$cells (Supplementary Table 1). Among these human $\mathrm{CD}_{4}{ }^{+}$cells, $40.8 \%$ were $\mathrm{CD}^{+} \mathrm{T}$ cells (Supplementary Table 1 ). These mice were then infected with HIV-1 (Fig. 3c). Recent data suggest that the establishment of refractory viral reservoirs takes place rapidly in human HIV-1 patients and in SIV-infected rhesus monkeys ${ }^{4,5}$. We examined some Hu-HSC mice 10 days after HIV-1 infection. Stimulation of splenocytes with PHA induced the expression of HIV-1 mRNA and production of Gag p24 in $\mathrm{CD}^{+} \mathrm{T}$ cells (Supplementary Fig. 4b, c). Although HIV-1 protein expression could still be detected in some T cells before the start of ART, these data suggest that latent HIV-1 infection has been established in human $\mathrm{CD}^{+}{ }^{+} \mathrm{T}$ cells in these $\mathrm{Hu}-\mathrm{HSC}$ mice.

We then determined the effects of SECH treatments in these mice in vivo. SECH treatments contained IDB $(2.5 \mathrm{mg} / \mathrm{kg}$ b.w.), ABT-263 (50 mg/kg b.w.), and SAR405 (50 mg/kg b.w.) formulated in a solvent mixture $10 \%$ ethanol, $30 \%$ polyethylene glycol 400, and 60\% Phosal 50 PG (EPP) for delivery into mice by oral gavage. Pilot experiments with administration of these doses of drugs to wild type C57BL/7 mice or in NSG-SGM3-derived HSC-Hu mice daily for 2 weeks showed no loss of body weight or other adverse effects on mice. SECH treatment was started at day 10 post infection once every 2 days as one cycle of treatments (Fig. 3c). Raltegravir and BMS-663068 (20 mg/kg b.w.) were included as the ART regimen daily. Mice in the control group received ART only daily.

We monitored HIV-1 mRNA in the mouse peripheral blood by RT-PCR. The purpose of ART included in the SECH protocol was to prevent the spread of HIV to uninfected cells, but not to decrease the production of new HIV-1 from infected cells induced by virus reactivation (Fig. 3a). We observed a burst of new $\mathrm{HIV}-1$ production induced by virus reactivation in the SECH group (Fig. 3d). A decline in HIV-1 mRNA detected in the blood would suggest a reduction in the HIV-producing cell pool. Indeed, we found that HIV-1 in the peripheral blood decreased after 25-32 cycles of SECH treatments (Fig. 3d). Between 32 and 40 cycles of SECH treatments, most mice treated by SECH showed either reduced or undetectable HIV-1 in the peripheral blood (Fig. 3d). As expected, mice in the ART-treated group showed low or undetectable HIV-1 throughout the treatments (Fig. 3d).

Determination of HIV-1 clearance in Hu-HSC mice. To determine whether HIV-1-producing cells were cleared in 
a

(1) Latency reversion IDB
(2)

ABT-263<smiles>C[13C](C)Br</smiles>

$\mathrm{Bcl}-\mathrm{xL}$<smiles>C1CCC1</smiles>

Host cell death

(3)

SAR405

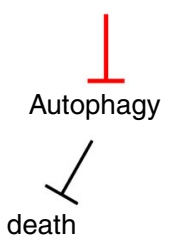

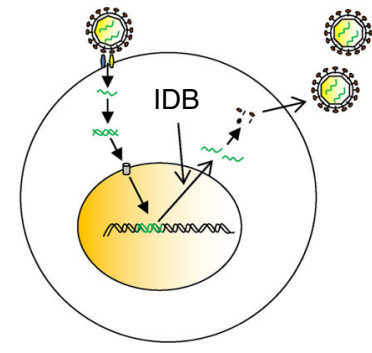

(4) BMS-663068

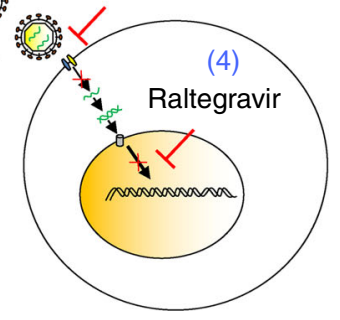

b

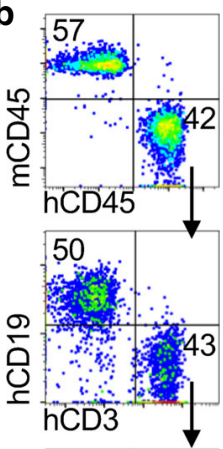

10

C

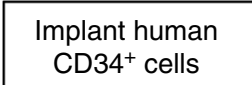

SECH treatment (every 2 days) CD34 ${ }^{+}$cells

$\downarrow$

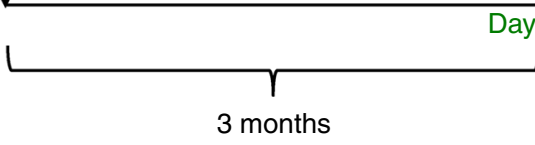

Measure blood HIV-1

f

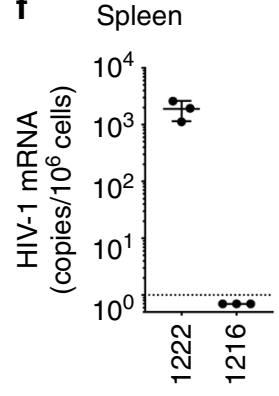

๑ $1201 \leftrightarrow 1209$

$\because 1202$ ษ 1210

$\diamond 1203 \oplus 1211$

$\rightarrow 1204 \div 1212$

$\bullet 1205-1213$

$\triangle 1206 \circledast 1214$

$\star 1207 \varangle 1215$

$\nabla 1208 \bowtie 1216$

Cycles

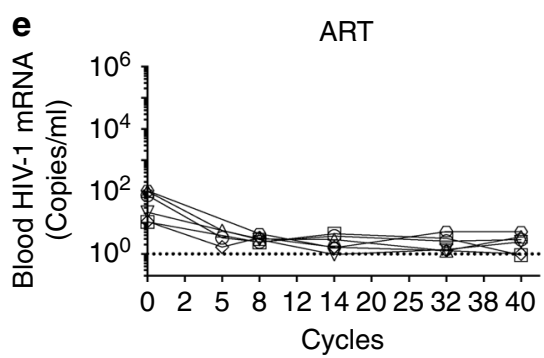

$$
\begin{aligned}
& \bullet 1217 \\
& \forall 1218 \\
& \bullet 1219 \\
& \bullet 1220 \\
& \varangle 1221 \\
& \forall 1222
\end{aligned}
$$
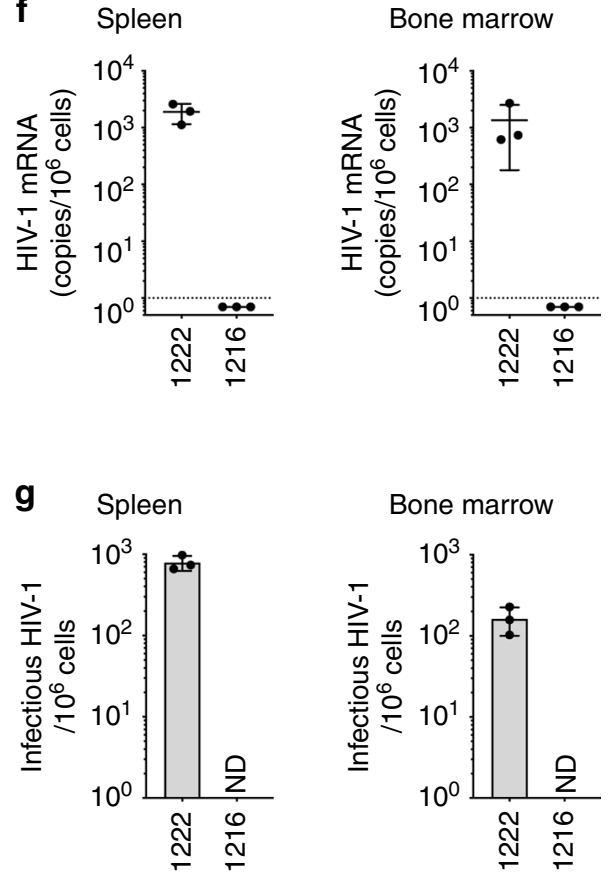

Fig. 3 Treatment of HIV-1 infections in Hu-HSC mice by SECH. a The SECH regimen includes: (1) latency reversion; (2) induction of cell death; (3) inhibition of autophagy; and (4) blocking of new infections with inhibitors for HIV-1 attachment and integration. $\mathbf{b}$ An example of flow cytometry analyses of human cells in the peripheral blood of NSG-SGM3 mice 3 months after reconstitution with human $\mathrm{CD}_{3} 4^{+}$stem cells. Cell negative for mouse CD45 (mCD45) and positive for human CD45 (hCD45) were gated to analyze CD19+ human B cells, $\mathrm{CD} 3^{+} \mathrm{CD} 4^{+}$, and $\mathrm{CD}^{+} \mathrm{CD} 8^{+}$human $\mathrm{T}$ cells. c Three months after reconstitution with human $\mathrm{CD}_{3} 4^{+}$stem cells, one set of HIV-1-infected Hu-HSC mice (Supplementary Table 1) were infected with HIV-1 (AD8 strain, 1000 pfu/mouse) intraperitoneally. Ten days after HIV-1 infections, the mice were used for treatments by ART or SECH. d, e RNA from the whole blood (including plasma and cells) was extracted to measure HIV-1 mRNA in mice treated by SECH e or ART f for 40 cycles. The dash line indicates detection limit. $\mathbf{f H I V}-1$ mRNA in the spleen and bone marrow of mice treated by SECH or ART was determined by RT-PCR. Data are presented as mean \pm SD ( $n=3$ technical replicates). ND, not detectable. $\mathbf{g}$ Infectious HIV-1 in the spleen and bone marrow of mice treated by SECH or ART was measured by TZA assays. Data are presented as mean \pm SD ( $n=3$ technical replicates). Source data are provided as a Source Data file. 

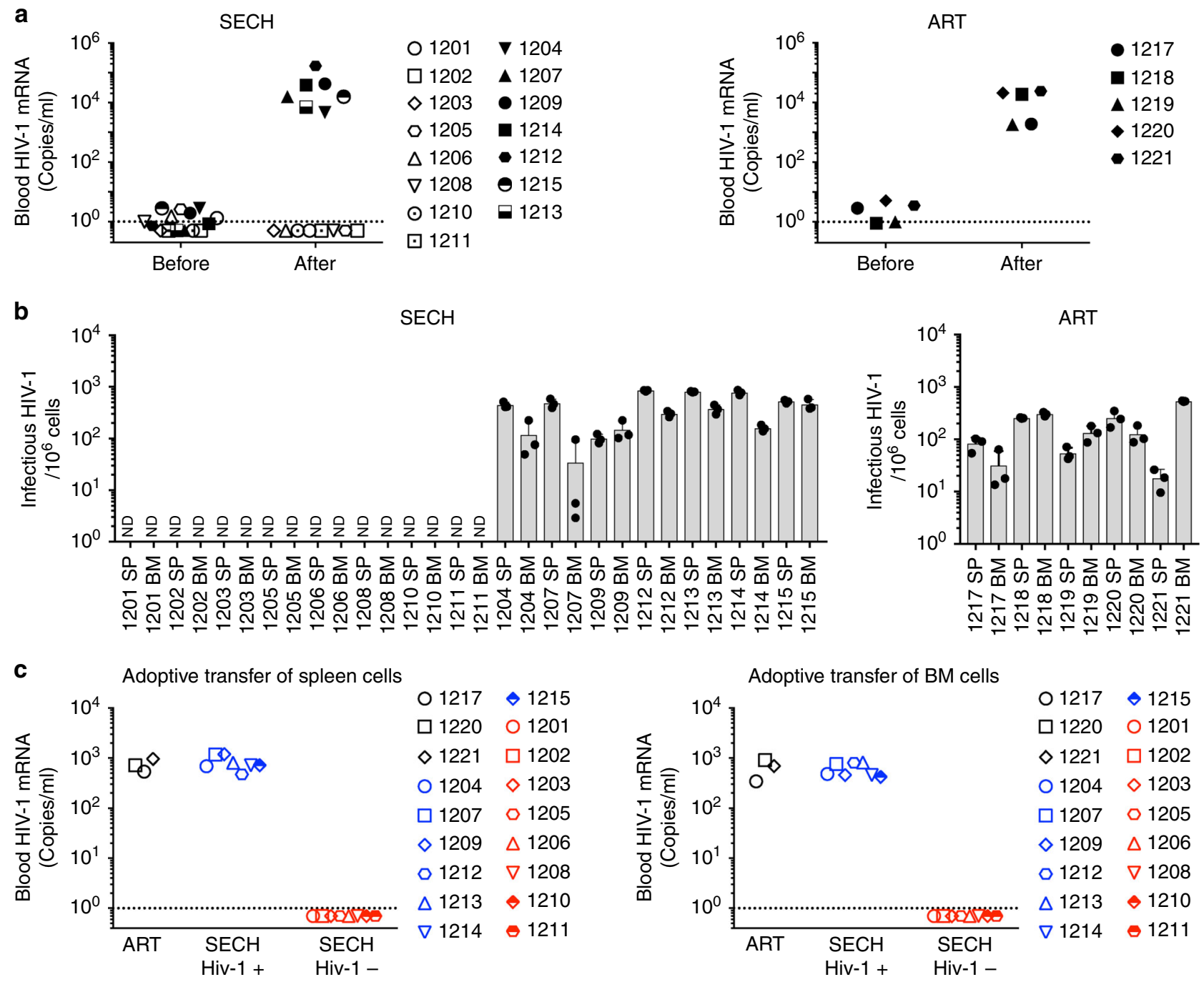

$\begin{array}{ll}\circ 1217 & \diamond 1215 \\ \square 1220 & \circ 1201 \\ \diamond 1221 & \square 1202 \\ \circ 1204 & \diamond 1203 \\ \square 1207 & \diamond 1205 \\ \diamond 1209 & \Delta 1206 \\ \circ 1212 & \nabla 1208 \\ \Delta 1213 & \diamond 1210 \\ \nabla 1214 & \diamond 1211\end{array}$

Fig. 4 Clearance of HIV-1 infections in Hu-HSC mice by SECH. a HIV-1 viral RNA levels in the blood of SECH- or ART-treated Hu-HSC mice before and after 2 months of withdrawal of the treatments (ART, $n=5 ; \mathrm{SECH}, n=15$ ). The dash line indicates detection limit. $\mathbf{b}$ Measuring infectious HIV-1 from spleen and bone marrow (BM) cells of HIV-1-infected Hu-HSC mice by TZA. Data are presented as mean \pm SD (ART, $n=5$ mice; SECH, $n=15$ mice). Data are presented as mean \pm SD. Each biological sample was measured in three technical replicates. ND, not detectable. $\mathbf{c}$ Virus outgrowth assay after adoptive transfer of spleen and BM cells from mice as in $\mathbf{c}$ into uninfected Hu-HSC recipient mice. (ART, $n=3$ mice; SECH, $n=15$ mice). Source data are provided as a Source Data file.

Hu-HSC after 40 cycles of SECH treatments, we examined HIV-1 in the spleen and bone marrow from mouse 1216 treated by SECH and mouse 1222 treated by ART. We could detect HIV-1 mRNA in the spleen and bone marrow of mouse 1222 but not mouse 1216 (Fig. 3f). TZM-bl cells stably expressing CD4, CCR5, CXCR4, and carrying a $\beta$-galactosidase gene under the control of HIV-1 long terminal repeat promoter have been used for more sensitive detection of replication-competent HIV-1 than traditional virus outgrowth assays or quantitative RT-PCR ${ }^{49,50}$. By this highly sensitive TZM-bl cell-based galactosidase reporter analysis (TZA) assay, we detected infectious HIV-1 in the spleen and bone marrow cells of mouse 1222 but not mouse 1216 (Fig. 3g). These results indicate that infectious HIV-1 is present in mouse 1222 treated by ART, but absent in mouse 1216 treated by SECH.

To further determine whether HIV-1 was cleared in Hu-HSC, SECH treatments were stopped after 40 cycles, followed by 2 months of withdrawal of treatments. We then measured HIV-1 in the peripheral blood of these mice. Eight mice were found to be negative for HIV-1 in the blood, whereas seven mice showed HIV-1 rebound after withdrawal of SECH (Fig. 4a). We found that those mice with no HIV-1 rebound in the blood also did not produce HIV-1 from spleen and bone marrow cells by the TZA assay (Fig. $4 \mathrm{~b}$ ). In contrast, all mice treated by ART showed virus rebound (Fig. 4a, b). In SECH-treated mice lacking detectable HIV-1 in the spleen and bone marrow, RT-PCR also showed no detectable HIV-1 in the lung, liver, and kidney (Supplementary Fig. 5a). Clearance of infectious HIV-1 is correlated with a decrease in HIV-1 DNA (Supplementary Fig. 5b). Lower levels of viral DNA are consistent with the clearance of productive HIV-1. The remaining viral DNA in mice with the clearance of productive infection likely represents non-productive HIV infection $^{51}$. Consistent with this possibility, an HIV-1 patient treated by stem cell transplantation is free of the infectious virus but still contains residual HIV-1 DNA in the tissues ${ }^{52}$. These observations support the conclusion that HIV-1 cure can be achieved by clearing replication-competent HIV-1 without removing the non-productive virus. Intracellular staining of $\mathrm{T}$ cells also showed the lack of p24 production in mice free of HIV-1 (Supplementary Fig. 6a). In contrast, all mice with HIV-1 rebound showed HIV-1 production in spleen and bone marrow 
cells (Fig. 4b). All mice treated by ART also remained $\mathrm{HIV}-1^{+}$ (Fig. 4a, b). This indicates that HIV-1 was cleared from $>50 \%$ of $\mathrm{Hu}-\mathrm{HSC}$ mice treated by SECH. In contrast, ART did not clear HIV-1 although it could control active viral production. In parallel experiments, we observed that HIV-1 infections in $\mathrm{Hu}-$ HSC mice could be suppressed by ART (Supplementary Table 2, Supplementary Fig. 5c). Further treatments by SECH could clear HIV-1 in an apportion of these mice, as shown by lack of virus rebound after withdrawal of the treatments, and by TZA assays (Supplementary Fig. $5 \mathrm{~d}-\mathrm{g}$ ). This suggests that SECH is potentially effective for treating HIV-1 infections with or without prior ART treatments.

Validation of HIV clearance by an in vivo outgrowth assay. In an in vivo humanized mouse-based-virus outgrowth assay (hmVOA) through adoptive transfer of HIV-1-infected cells into humanized mice, the preformed lymphoid organs in the recipients provides highly sensitive detection of latent HIV-1 infections ${ }^{14,53,54}$. To further confirm virus clearance in the SECH-treated mice, we transferred spleen and bone marrow cells from these mice into uninfected Hu-HSC mice. Consistent with the in vitro TZA assay, HIV-1 was not detected by hmVOA in uninfected recipients after adoptive transfer of spleen or bone marrow cells from HIV-1-negative mice (Fig. 4c). In contrast, all Hu-HSC mice became HIV-1 ${ }^{+}$after receiving spleen or bone marrow cells from HIV $-1^{+}$mice (Fig. 4c). These data demonstrate that mice negative for HIV-1 by TZA assay were indeed free of virus by in vivo virus outgrowth assay in recipient $\mathrm{Hu}-$ HSC mice. These results suggest that the SECH treatments led to the elimination of HIV-1 infections in 8 out of $15 \mathrm{Hu}-\mathrm{HSC}$ mice as shown by the lack of virus rebound after withdrawal of SECH treatments, and the lack of infectious viruses by in vitro TZA assay and by in vivo hmVOA assay. We observed no significant loss of body weight in these mice after SECH or ART treatments (Supplementary Fig. 6b). We also observed no signs of inflammation or other histological changes in the brain, liver, lung, and kidney of these mice after SECH treatments (Supplementary Fig. 6c). SECH- and ART-treated mice showed overall comparable levels of human $\mathrm{CD} 19^{+} \mathrm{B}$ cells and $\mathrm{CD} 4^{+}$or $\mathrm{CD}^{+} \mathrm{T}$ cells (Supplementary Fig. 7a). In SECH-treated mice, there were increases in $\mathrm{CD}_{45 \mathrm{RO}^{+} \mathrm{CCR}^{-}}{ }^{-} \mathrm{EMT}$ cells and $\mathrm{CD}^{4} 5 \mathrm{RO}^{-} \mathrm{CCR}{ }^{-}$ effector $\mathrm{T}$ cells, whereas $\mathrm{CD} 45 \mathrm{RO}^{+} \mathrm{CCR}^{+}{ }^{+} \mathrm{CMT}$ cells and $\mathrm{CD} 19^{+}$ $\mathrm{CD}^{2} 7^{+}$memory B cells were still present (Supplementary Fig. $7 \mathrm{~b}$ ). These results indicate that SECH is safe for treating HIV1-infected Hu-HSC mice to clear HIV-1 infections.

Synergy between JQ1 and IDB in HIV-1 clearance by SECH. Why HIV-1 is only cleared in a portion of the infected $\mathrm{Hu}-\mathrm{HSC}$ mice is unclear. It is possible that improving HIV-1 reactivation induced by IDB could promote viral clearance. Bromodomain containing 4 is a negative regulator of transcription factor PTEF-b required for HIV-1 gene expression ${ }^{55}$. JQ1, an inhibitor for the BET family of bromodomains, can promote the reactivation of HIV $-1^{56}$. Consistent previous observations ${ }^{57}$, we observed that using JQ1 and IDB together induced better reactivation of HIV-1 from latently infected $\mathrm{T}$ cells (Supplementary Fig. 8a). We therefore investigated whether including the epigenetic modifier JQ1 could increase the efficacy of SECH treatment.

We compared SECH treatments with or without the inclusion of JQ1 in HIV-1-infected Hu-HSC mice. Hu-HSC mice were reconstituted with an average of $35.6 \%$ human $\mathrm{CD}^{+} 5^{+}$cells (Supplementary Table 3). Among human CD $45^{+}$cells, $46.6 \%$ were $\mathrm{CD}^{+} \mathrm{T}$ cells (Supplementary Table 3). After the initial burst of HIV-1 mRNA induced by virus reactivation by SECH, all mice showed either low or undetectable HIV-1 in the peripheral blood after 35 cycles of SECH treatments (Fig. 5a). After 2 months of withdrawal of treatments, 4 out of 10 mice in the SECH group without JQ1 showed no HIV-1 rebound (Fig. 5b). Interestingly, 10 out of 13 mice showed no virus rebound when JQ1 was included in the SECH treatments (Fig. 5b). No HIV-1 production was detected in the spleen and bone marrow cells from these HIV-1-negative mice by TZA assay (Fig. 5c). Moreover, HIV-1 was not detected by hmVOA assays after adoptive transfer of spleen and bone marrow cells from these HIV-1negative mice into $\mathrm{Hu}-\mathrm{HSC}$ recipients (Fig. 5d). In contrast, HIV$1^{+}$mice after SECH treatments and all ART-treated mice produced HIV-1 by in vitro TZA and in vivo hmVOA assays (Fig. 5c, d). In addition,, we observed no significant differences in body weight, tissue sections and the total numbers of $\mathrm{T}$ or $\mathrm{B}$ cells in these mice after treatment by SECH or ART (Supplementary Fig. $8 \mathrm{~b}-\mathrm{d}$ ). These results suggest that inclusion of JQ1 together with IDB for latency reversal can enhance the efficacy of HIV-1 clearance by SECH.

Clearance of HIV-1 in PBMCs of HIV-1-infected patients. We next determined whether SECH could be used to clear HIV-1 infections in PBMCs from HIV-1-infected patients. We examined PBMCs from 10 ART-naive HIV-1 patients who had not received previous antiretroviral treatments. Five of these patients have relatively normal $\mathrm{CD}^{+}{ }^{+} \mathrm{T}$-cell counts $(>500 / \mu \mathrm{l}$ blood), whereas four showed severely depletion of CD $4^{+} \mathrm{T}$ cells $(<200 / \mu$; Fig. $6 \mathrm{a})$. PBMCs from each patient were separated into two fractions for treatments by either SECH or ART, with a 2-day culture as one cycle of treatments. After seven cycles of treatments, HIV-1 was undetectable in PBMCs treated by SECH, but remained detectable after treatment by ART (Fig. 6b). Consistent with RT-PCR analyses, SECH-treated PBMCs did not produce HIV-1 after adoptive transfer into $\mathrm{Hu}-\mathrm{HSC}$ recipient mice, whereas the same patient samples treated by ART produced the virus in the recipients (Fig. 6c). TZA assays also showed the lack of infectious HIV-1 in cells treated by SECH (Fig. 6d). This suggests that the SECH treatments successfully eliminated HIV-1 in the blood samples of HIV-1-infected patients.

We also examined PBMCs from outpatients undergoing ART treatments at the Houston Methodist Hospital (Fig. 7a). Although PBMCs of these patients showed no active virus production, HIV-1 could be detected after stimulation with IDB (Fig. 7b, Supplementary Fig. 9a), suggesting that these patients harbored latent HIV-1 infections. After five cycles of treatments by SECH, we observed that HIV-1 was absent in PBMCs from these patients as shown by RT-PCR (Fig. 7b), indicating that SECH is effective for clearing HIV-1 in PBMCs from ART-treated patients. To confirm this finding, we next performed adoptive transfer of treated PBMCs into uninfected $\mathrm{Hu}-\mathrm{HSC}$ mice for in vivo hmVOA assay. We found that SECH-treated PBMCs from these patients did not produce HIV-1, whereas all ART-treated samples were $\mathrm{HIV}-1^{+}$by hmVOA (Fig. 7c). Consistently, TZA assays also showed that the cells treated by SECH did not produce infectious HIV-1 (Fig. 7d). SECH treatment without the inclusion of ART drugs failed to clear HIV-1 (Supplementary Fig. 9b), suggesting that blocking new viral infections is critical for the success of SECH. Similar to our earlier observations for in vitro cultures (Fig. 2e), the cell viabilities and total live cells of patient PBMCs were similar between untreated controls and samples treated by SECH or ART (Supplementary Fig. 9c). Interestingly, the levels of total T cells were comparable between samples treated by SECH and ART (Supplementary Fig. 9d). Memory B cells were comparable in samples treated by SECH and ART (Supplementary Fig. 9e). In SECH-treated samples, there were increases in $\mathrm{CD}^{2} 5 \mathrm{RO}^{+} \mathrm{CCR}^{-}$EMT cells and $\mathrm{CD}^{-} 5 \mathrm{RO}^{-} \mathrm{CCR}^{-}$effector 


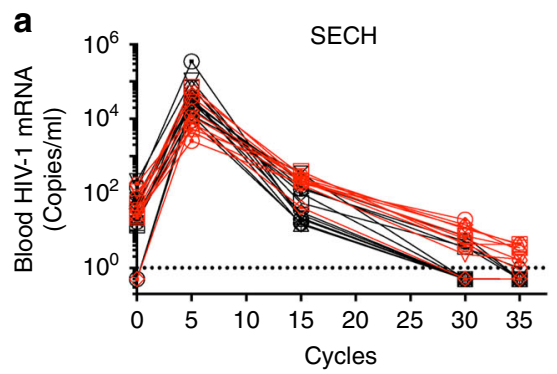

$$
\begin{aligned}
& \odot 1301 \diamond 1309 \text { ๑ } 1317 \\
& \square 1302 @ 1310 \text { ๑1318 } \\
& \diamond 1303 \text { ๑ } 1311 \leftrightarrow 1319 \\
& \bullet 1304 \boxminus 1312 \oplus 1320 \\
& \triangle 1305 \diamond 1313 \otimes 1321 \\
& \nabla 1306 \ominus 1314 \bigotimes 1322 \\
& \text { ๑) } 1307 \bowtie 1315 \diamond 1323
\end{aligned}
$$

b

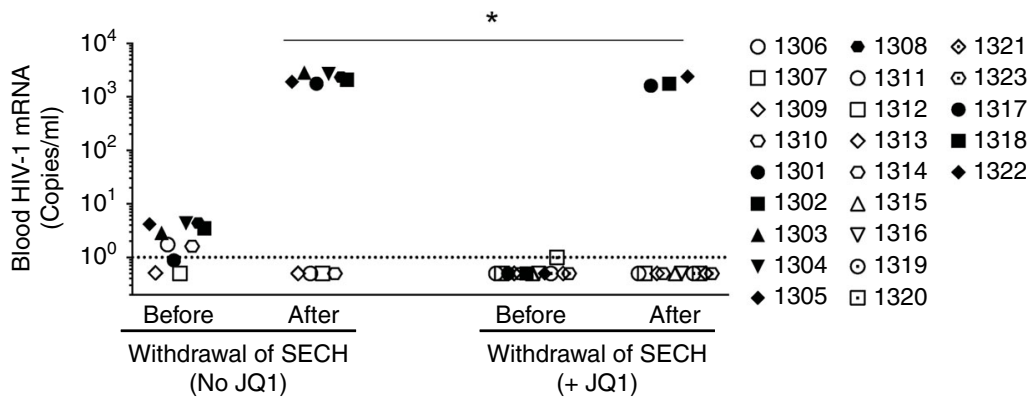

C

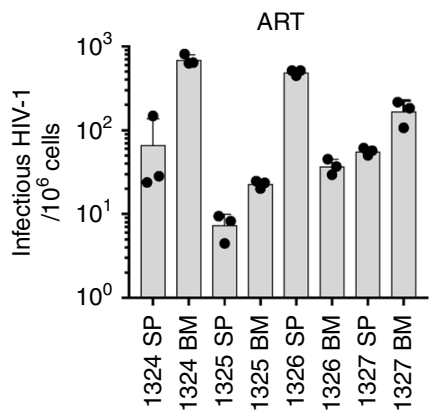

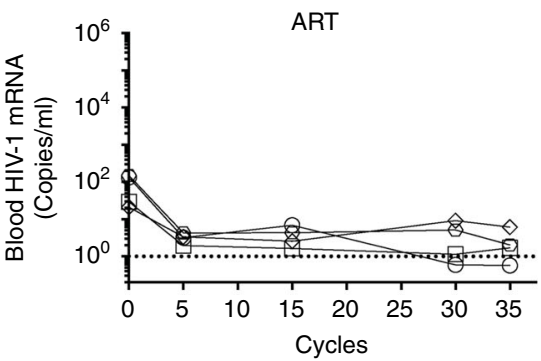

$\ominus 1324$

$\square 1325$

$\diamond 1326$

$\ominus 1327$
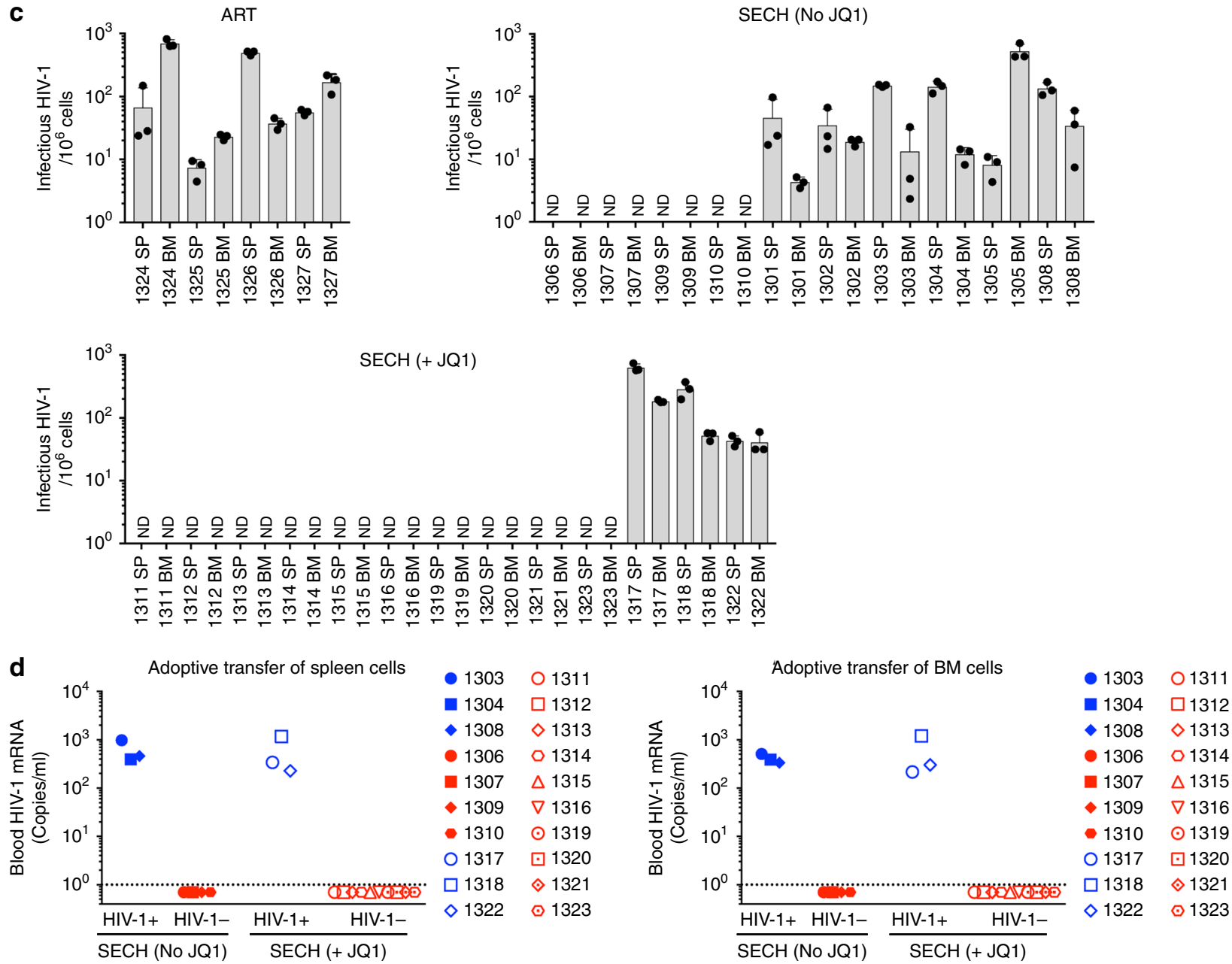

Fig. 5 Improvement of SECH treatment by inclusion of JQ1. a Viral RNA levels in one set of HIV-1-infected Hu-HSC mice (Supplementary Table 3) orally treated by SECH with (black symbols) or without JQ1 (red symbols) for a total of 35 cycles (ART, $n=5$ mice; SECH, $n=10$ mice; SECH + JQ1, $n=13$ mice). The dash line indicates detection limit. $\mathbf{b}$ Viral titer in the blood before and after withdrawal of the treatments. $(\mathrm{SECH}, n=10 \mathrm{mice} ; \mathrm{SECH}+\mathrm{JQ1}, n=13$ mice). No JQ1 vs. JQ1, $p=0.0407$ (Mann-Whitney test). c Measuring infectious HIV-1 from spleen and bone marrow cells of HIV-1-infected Hu-HSC mice by TZA. Biological samples from each mouse were measured in three technical replicates. Data are presented as mean \pm SD (ART, $n=5$ mice; SECH, $n=$ 10 mice; SECH + JQ1, $n=13$ mice). ND, not detectable. $\mathbf{d}$ hmVOA for spleen and bone marrow cells from mice in $\mathbf{c}(\mathrm{SECH}, n=7$ mice; SECH + JQ1, $n=13$ mice). Source data are provided as a Source Data file. 


\begin{tabular}{ccccccccc}
\hline a Patient ID & Race & Sex & Age & CD4 Counts & CD4 (\%) & CD19 (\%) & CD3 (\%) & $\begin{array}{r}\text { HIV RNA Levels } \\
\text { (copies/ml) }\end{array}$ \\
\hline 1 & C & M & 46 & 116 & 6.4 & 1.4 & 86.7 & $>750,000$ \\
2 & B & M & 36 & 735 & 32.0 & 6.0 & 75.2 & 4635 \\
3 & C & M & 27 & 1030 & 31.9 & 5.3 & 67.1 & 6400 \\
4 & C & F & 21 & 1289 & 39.3 & 1.0 & 82.1 & $<400$ \\
5 & C & M & 67 & 127 & 9.5 & 2.9 & 79.1 & 6831 \\
6 & A & M & 36 & 629 & 31.2 & 11.5 & 73.6 & 9550 \\
7 & C & F & 55 & 21 & 3.8 & 24.3 & 59.5 & $>750,000$ \\
8 & C & M & 54 & 231 & 23.1 & 4.0 & 87.9 & 47931 \\
9 & B & M & 33 & 506 & 16.8 & 5.0 & 83.0 & 24083 \\
10 & C & M & 32 & 23 & 2.1 & 17.1 & 64.3 & 167,638 \\
\hline
\end{tabular}
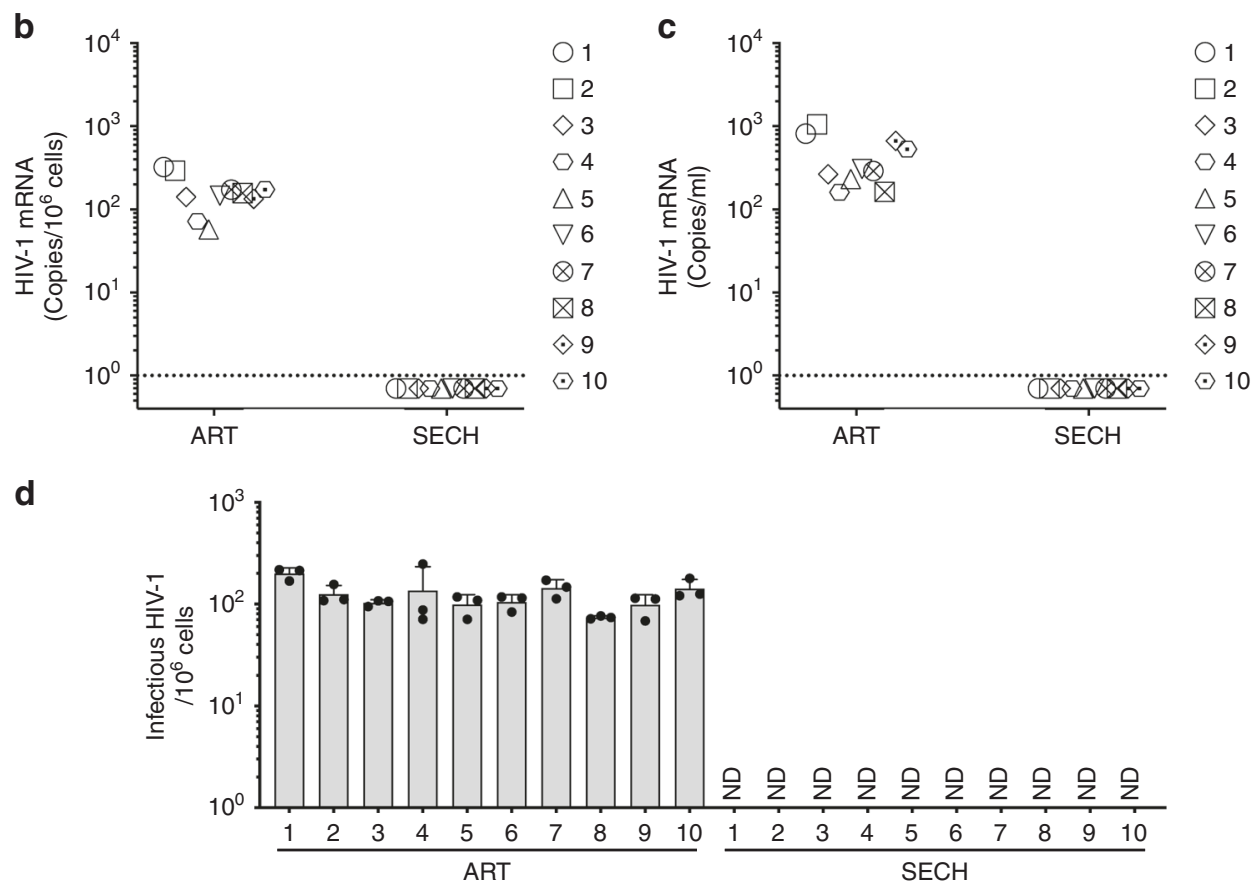

Fig. 6 Clearance of HIV-1-infected cells from ART-naive HIV-1 patients by SECH treatments in vitro. a CD4 counts and HIV-1 load in ART-naive HIV-1infected patients $(n=10)$ without previous antiretroviral treatment. A, Asian; B, Black; C, Caucasian. b PBMCs obtained from ART-naive HIV-1 patients ( $n$ =10) were culture in vitro with agents for SECH or ART only for 2 days as on cycle, with a total of seven cycles as described in the "Method" section. Samples were also re-stimulated with IDB for detection of HIV-1 mRNA by RT-PCR. The dash line indicates detection limit. $\mathbf{c}$ PBMCs treated by in $\mathbf{b}$ were depleted of CD8 ${ }^{+} T$ cells and $3 \times 10^{6}$ cells were adoptively transferred into uninfected Hu-HSC mice for detection of HIV- 1 by hmVOA. $\mathbf{d}$ The cells treated in $\mathbf{b}$ were used for TZA analyses. Ten biological samples were each measured in three technical replicates and presented as mean \pm SD. Source data are provided as a Source Data file.

T cells, while $\mathrm{CD} 45 \mathrm{RO}^{+} \mathrm{CCR}^{+}{ }^{+} \mathrm{CMT}$ cells were not significantly changed (Supplementary Fig. 9f). This indicates that SECH treatments killed infected T cells but not uninfected cells. SECH therefore can potentially be developed into an effective strategy to treat HIV-1 infections.

\section{Discussion}

We show that it is feasible to clear HIV-1 infection by the SECH approach through selective elimination of host cells capable of producing the virus. This method combines agents that reactivate HIV-1, promote cell death, and inhibit autophagy, together with ART to prevent new infections. Continuous cycles of $\mathrm{SECH}$ treatments cleared HIV-1 infection in over $50 \%$ of $\mathrm{Hu}-\mathrm{HSC}$ mice in vivo. HIV-1 clearance was confirmed by a lack of virus rebound after withdrawal of SECH treatments, in vitro TZA assays, and in vivo virus outgrowth assay by adoptive transfer of the spleen and bone marrow cells from treated mice into uninfected humanized mice. HIV-1 was cleared in PBMCs from HIV-1-infected patients with or without prior ART treatments by SECH, as determined by TZA assays and humanized mouse-based virus outgrowth assay. Our study suggests a strategy for the eradication of HIV-1 infection by selectively eliminating the infected cells that are capable of producing new viruses.

The SECH approach can delete HIV-1-infected cells while preserving the uninfected healthy cells. Mechanistically, activation of T cells with a latency reversing agent, IDB, led to caspase activation and cell death signaling in HIV-infected cells, whereas sparing the uninfected cells (Fig. 2a, e). Applying IDB has an unintended effect of inducing antiapoptotic molecules and autophagy, which likely inhibit the killing of HIV-1-infected cells (Fig. 2a). ABT-263 and SAR405 are used to mitigate these unintended effects of IDB to promote cell death in HIV-infected cells. Nevertheless, the induction of antiapoptotic molecules and autophagy by IDB may have the benefit of conferring protection of uninfected cells against killing, thereby improving the specificity of the SECH approach in targeting HIV-1-infected cells. An epigenetic modifier, JQ1, could be included in SECH to synergize with IDB for HIV-1 reactivation to promote the clearance of HIV-1-producing cells. Preferential killing of HIV-1-infected cells 
a

\begin{tabular}{ccccrrc}
\hline Patient & Race & Sex & Age & CD4 Count & CD4\% & $\begin{array}{c}\text { HIV RNA Levels } \\
\text { (copies/mL) }\end{array}$ \\
\hline 11 & B & M & 33 & 447 & 9 & ND \\
12 & B & M & 31 & 501 & 20 & ND \\
13 & B & F & 50 & 18 & 6 & ND \\
14 & B & F & 43 & 941 & 39 & ND \\
15 & B & M & 53 & 28 & 18 & $<20$ \\
16 & C & M & 56 & 451 & 26 & ND \\
17 & C & M & 66 & 935 & 39 & ND \\
18 & B & F & 47 & 898 & 54 & ND \\
19 & B & F & 55 & 1049 & 29 & ND \\
20 & B & F & 39 & 128 & 13 & ND \\
\hline
\end{tabular}

b

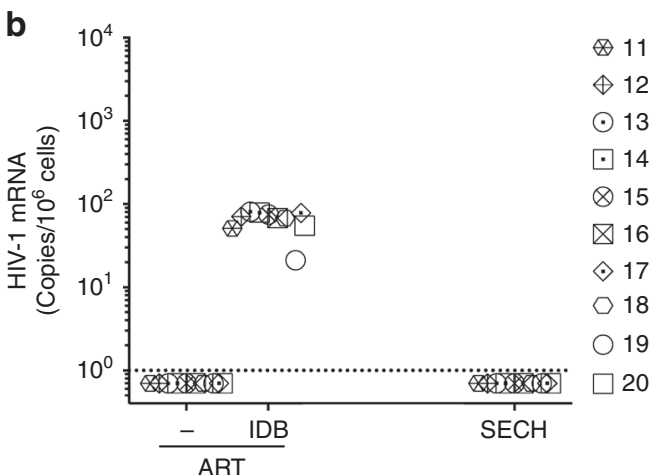

d

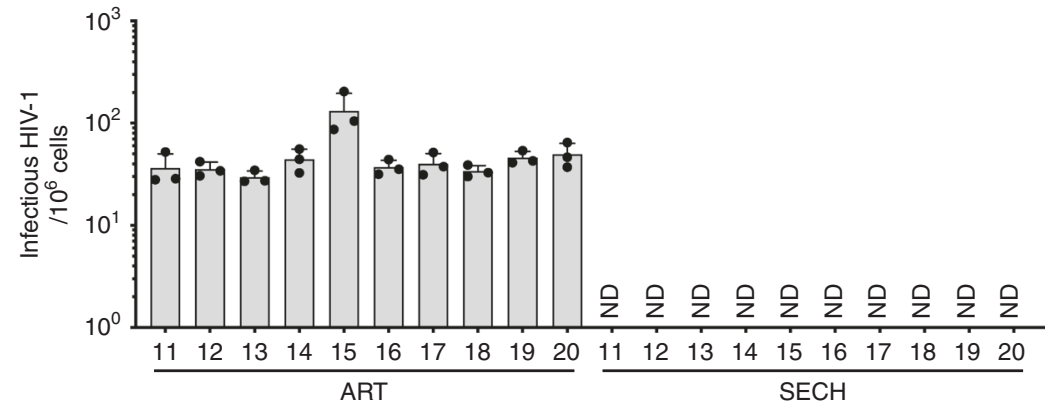

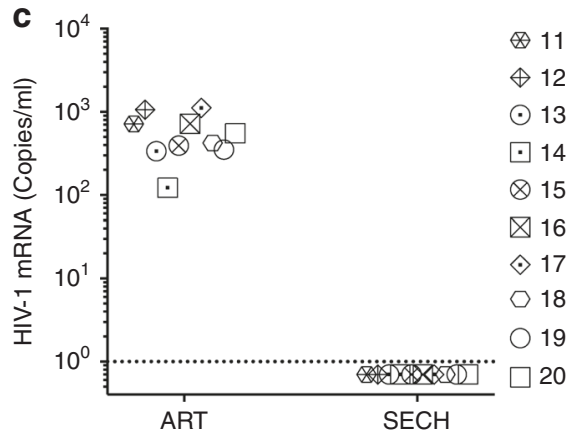

Fig. 7 Clearance of HIV-1-infected cells from ART-experienced HIV-1 patients by SECH treatments in vitro. a CD4 counts and HIV-1 load in ARTexperienced HIV-1-infected patients $(n=10)$. HIV viremia was successfully suppressed in all patients at the time of blood collection. Patients 18 and 19 had undergone ART treatments for 139 and 95 days, respectively. b-d PBMCs from ART-experienced HIV-1 patients $(n=10)$ were treated with SECH or ART and then used for detection of HIV-1 mRNA by RT-PCR $\mathbf{b}$ hmVOA $\mathbf{c}$ and TZA analyses $\mathbf{d}$ as in Fig. 6. Ten biological samples were each measured in three technical replicates and presented as mean \pm SD d. Source data are provided as a Source Data file.

and protection of uninfected cells are important for the selectivity and safety of this SECH method, resulting in the eradication of HIV reservoir while preserving a normal immune cell repertoire.

Although the agents for SECH can cause rapid and specific clearance of HIV-1-infected cells in vitro (Figs. 2e, 6 and 7), the efficacy in vivo is expected to be lower. Indeed, we observed that clearance of HIV-1 reservoirs in different sets of HIV-1-infected $\mathrm{Hu}-\mathrm{HSC}$ mice ranged from 40 to $70 \%$ (Figs. 3-5 and Supplementary Fig. 5). The pharmacokinetics for these drugs in vivo and the duration of effective drug concentrations present in different tissues remain to be characterized. This will help to determine the optimal doses and frequency of treatments. Inclusion of epigenetic modifier JQ1 further increased HIV-1 reactivation and clearance (Fig. 5, Supplementary Fig. 8a), suggesting that increased virus reactivation can improve the success rate of viral clearance by SECH. Therefore, promoting virus reactivation represents one effective way for improving the success rate of $\mathrm{SECH}$ in HIV-1 clearance in vivo. Testing alternative latency reversal drugs may reveal better approaches for virus reactivation to facilitate the clearance of HIV-1 reservoirs.

Autophagy is essential for the protection of long-term maintenance of memory $\mathrm{T}$ cells and memory $\mathrm{B}$ cells ${ }^{25-28,58}$, and promoting the longevity of other cell types as well ${ }^{59}$. It has been shown that autophagy can regulate HIV-1 replication during persistent infection $^{60,61}$. We found that autophagy did not affect HIV-1 reverse transcription, integration into host genome or reactivation. Rather, inhibition of autophagy promoted caspase activation and cell death induced by virus reactivation with IDB (Fig. 1h, i and Fig. 2b-d). Suppressing autophagy would likely remove a major protective mechanism for memory $\mathrm{T}$ cells harboring latent HIV-1, thereby unleashing the cell death machinery triggered by viral replication and by addition of apoptosis inducers.

Despite enormous challenges, the development of HIV-1 vaccines has shown great promises in inducing immune protection against the virus ${ }^{62,63}$. Broad-spectrum neutralization antibodies are valuable in inhibiting viremia by neutralizing HIV $-1^{64}$. Use of CAR 
T cells to target HIV-1 proteins can suppress HIV-1 infections in humanized mice or patient samples ${ }^{65,66}$. In addition to blocking viral fusion with cell membranes and integration into host genome, broad neutralizing antibodies may be used to replace agents for ART to prevent new infections during SECH treatments.

We show a SECH approach in a humanized mouse model to eradicate the HIV-1 reservoir by a combination of latency reversal, inhibition of autophagy, promotion of apoptosis, and blocking of new rounds of viral replication by ART. Continuous SECH treatments via the oral route can safely and effectively reduce and clear HIV-1 reservoirs established in humanized mice. Moreover, treating PBMCs from HIV-1 patients by SECH led to the successful clearance of HIV-1 infections. Our study suggests a cure strategy for treating HIV-1 infections by selectively eliminating host cells harboring replication-competent HIV-1.

\begin{abstract}
Methods
Flow cytometry. The following antibodies from Biolegend were used for flow cytometry: pacific blue-anti-mouse CD45 (1:100, 103126, clone 30-F11,) APC-antihuman CD45 (1:100, 304012, clone HI30), pacific blue-anti-human CD19 (1:100, 302232, clone HIB19), PE-anti-human CD4 (1:100, 317414, clone OKT4), APC/ Fire-750-anti-human CD8 (1:100, 34474, clone SK1), FITC-anti-human CD56 (1:100, 392413, clone QA17A16), pacific blue-anti-human CD19 (1:100, 302232, clone HIB19), pacific blue-anti-human CD3 (1:100, 300329, clone HIT3a), PE/Cy7anti-HLA-HLA-DR, DP, DQ (1:100, 361708, clone Tü39), PerCP/Cy5.5-antihuman CD11b (1:100, 301327, clone ICRF44), APC/Fire-750-anti-human CD163 (1:100, 333633, clone GHI/61), PE-anti-human CD123 (1:100, 306005, clone 6H6), Alexa Fluor 488 anti-human CD11c (1:100, 301618, clone 3.9), PerCP/Cy5.5-antihuman CD3 (1:100, 300328, clone HIT3a), PerCP/Cy5.5-anti-human CD123 (1:100, 306016, clone 6H6), FITC-anti-mouse CD45 (1:100, 103108, clone 30-F11), PE/Cy7-anti-human CD197 (CCR7) (1:100, 353226, clone G043H7), PE-antihuman CD45RO (1:100, 304244, clone UCHL1), FITC-anti-human CD45RA (1:100, 304148, clone HI100) and Alexa Fluor 488 anti-CD68 (1:30, 333812, clone Y1/82 A), PerCP/Cy5.5-anti-human CD19 (1:100, 302230, clone HIB19), PE-antihuman CD27 (1:100, 356406, clone M-T271), and pacific blue-anti-human IgD $(1: 100,348224$, clone IA6-2). PE-anti-human CD3 (1:100, 556612, clone SP34) and V50-anti-human CD4 (1:100, 560345, clone RPA-T4) were from BD Biosciences. The cells stained with indicated antibodies were analyzed using a BD LSR II flow cytometer (BD Biosciences). To detect HIV-1 p24, spleen cells from Hu-HSC mice were stimulated with $5 \mu \mathrm{g} / \mathrm{ml}$ PHA (Sigma) and $6 \mathrm{ng} / \mathrm{ml} \mathrm{IL-2} \mathrm{(Biolegend).} \mathrm{The} \mathrm{cells}$ were stained for T-cell markers, followed by fixation and permeabilization using the Cytofix/Cytoperm buffer (BD Bioscience) and intracellular staining with PEconjugated anti-p24 (1:30, 6604667, clone KC57, Beckman Coulter). The cells were analyzed by flow cytometry using a BD LSR II flow cytometer (BD Bioscience) and FlowJo software (version 10.5.3, BD Bioscience).
\end{abstract}

T-cell isolation and infection with HIV-1. PBMCs of anonymous healthy donors from the Gulf Coast Blood Center were used to purify $\mathrm{CD} 4{ }^{+} \mathrm{T}$ cells with anti-CD4 MACS beads (Miltenyi Biotec). $\mathrm{CD}^{+}{ }^{+} \mathrm{CD} 4{ }^{+} \mathrm{CD} 45 \mathrm{RA}{ }^{+} \mathrm{CD} 45 \mathrm{RO}^{-} \mathrm{CCR}^{+}$naive $\mathrm{T}$ cells, $\mathrm{CD}{ }^{+}{ }^{+} \mathrm{CD} 4{ }^{+} \mathrm{CD} 45 \mathrm{RA}^{-}{ }^{-} \mathrm{CD} 45 \mathrm{RO}^{+} \mathrm{CCR}^{+}{ }^{+} \mathrm{CMT}$ and $\mathrm{CD} 3{ }^{+} \mathrm{CD} 4{ }^{+} \mathrm{CD} 45 \mathrm{RA}$ ${ }^{-} \mathrm{CD} 45 \mathrm{RO}^{+} \mathrm{CCR}^{-}{ }^{-} \mathrm{EMT}$ were sorted using a BD FACSAria flow cytometer (BD Bioscience). Naive $\mathrm{CD}^{+} \mathrm{T}$ cells were stimulated with $5 \mu \mathrm{g} / \mathrm{ml}$ PHA and $6 \mathrm{ng} / \mathrm{ml}$ IL-2 in Rosewell Park Memorial Institute (RPMI) complete medium for 2 days to generate activated $\mathrm{CD} 4^{+} \mathrm{T}$ cells. Sorted $\mathrm{T}$-cell subsets or activated $\mathrm{T}$ cells were infected with HIV-1 CXCR4-tropic NL4-3 or CCR5-tropic AD8 (both virus clones were obtained from the NIH AIDS Reagent Program) at the indicated MOI for $2 \mathrm{~h}$. The cells were washed with PBS and cultured in RPMI complete medium containing $30 \mathrm{~nm}$ CCL19 (Biolegend) and $0.3 \mathrm{ng} / \mathrm{ml} \mathrm{IL-2} \mathrm{(Biolegend)} \mathrm{and} \mathrm{for} 4$ days to establish latent HIV infection as described ${ }^{29}$.

For gene silencing, CMT were transfected with 100 nm siRNA targeting Atg7 or control siRNA (Dharmacon) using the Neon Transfection System at 2150 volts with one pulse of $20 \mathrm{~ms}$ (Life Technologies). Virtually all cells were transfected using this condition with a fluorescently labeled siRNA. Gene silencing was confirmed by Western blot (Fig. 1a). The cells were infected with 0.1 MOI of HIV-1 (HIV-1 NL4-3) at $37^{\circ} \mathrm{C}$ for $2 \mathrm{~h}$. The cells were then cultured with CCL19 as above to establish HIV latent infection.

Naive T cells, activated T cells, CMT or EMT with or without infection with HIV-1 (NL4-3, 1 MOI) were cultured for 4 days in the presence of $30 \mathrm{~nm}$ CCL19 and $0.3 \mathrm{ng} / \mathrm{ml} \mathrm{IL-2} \mathrm{for} 4$ days to establish latent HIV infection. The cells with or without HIV-1 infections were stimulated with $0.1 \mu \mathrm{M}$ IDB (ENZO Life Sciences) in the presence of $0.2 \mu \mathrm{m}$ ABT-263 (Adooq Bioscience), $2 \mu \mathrm{m}$ SAR405

(MedChemExpress), or $10 \mu \mathrm{M} C Q$ (Sigma) as indicated for $48 \mathrm{~h}$. The cells were then incubated with $1 \mu \mathrm{M}$ FITC-DEVD-FMK (Biovision), followed by staining with APC-Annexin V (Biolegend) and intracellular staining with PE-anti-HIV p24. The cells were analyzed by flow cytometry. The percentage of cell death was calculated by the loss of live cells negative for annexin $\mathrm{V}$ and DEVD staining by comparing treated and untreated groups: (untreated-treated)/untreated $\times 100 \%$.

To determine the specificity in the killing of HIV-1 infected cells, uninfected CD4 cells were labeled with CellTrace Violet dye (ThermoFisher Scientific) and mixed with HIV-1-infected cells at the ratio of 1:1. The cells were resuspended in RIPMI complete medium containing $0.2 \mu \mathrm{m}$ BMS-626529, with $0.1 \mu \mathrm{M} \mathrm{IDB}, 0.2 \mu \mathrm{m}$ ABT-263, and $2 \mu \mathrm{M}$ SAR405 as indicated for $48 \mathrm{~h}$. The cells were incubated with 1 $\mu \mathrm{M}$ FITC-DEVD-FMK, followed by staining with APC-Annexin and analyses by flow cytometry.

CD4 cells with or without HIV-1 infection cultured with or without $1 \mu \mathrm{M}$ SAR405 for 12 hours and fixed in the $4 \%$ formaldehyde (ThermoFisher Scientific) The fixed cells were then incubated with rabbit anti-LC3A/B antibody (1:100, 12741 s, Cell Signaling Technology), followed by staining with Alexa Fluor 594 donkey anti-rabbit IgG (1:5000, A21207, Thermo Fisher Scientific). LC3 punctate in the cells were quantified under a fluorescent microscope.

Detection of HIV-1 DNA products of reverse transcription and proviral DNA integration. CMT at different hours after HIV-1 infection were used for PCR to detect HIV-1 reverse transcription products as described ${ }^{36}$, including early $R / U 5$ product, sense primer (5'-GGCTAACTAGGGAACCCACTG-3'), antisense primer (5'-CTGCTAGAGATTTTCCACACTGAC-3'), and late LTR-gag product, sense primer (5'-CAGATATCCACTGACCTTTGG-3'), antisense primer (5'-GCTTAAT ACTGACGCTCTCGCA- $3^{\prime}$ ). $\beta$-globin was detected by PCR with $\beta$-globin forward, $5^{\prime}$-CCCTTGGACCCAGAGGTTCT- $3^{\prime}$ and $\beta$-globin reverse, $5^{\prime}$-CGAGCACTTTC TTGCCATGA-3'. R/U5 and LTR-gag PCRs were normalized against $\beta$-globin. Genomic DNA from $\mathrm{CD}_{4}^{+} \mathrm{T}$ cells at 4 days after initial HIV-1 infections was used for real-time PCR for Alu-gag using the following primers ${ }^{37}$ : Alu forward primer (5'-GCCTCCAAAGTGCTGGGATTACAG-3') and $g a g$ reverse primer ( $5^{\prime}$ GTTCCTGCTATGTCACTTCC-3'). The relative levels of Alu-gag were normalized against $\beta$-globin.

Western blot. PBMC CD4 ${ }^{+} \mathrm{T}$ cells with or without infection by HIV-1 cultured for 4 days with CCL19 as in Fig. 1a. The cells were then cultured in the absence or presence of $0.1 \mu \mathrm{M} \mathrm{IDB}$ for $24 \mathrm{~h}$. The cells were lysed in lysis buffer containing 50 mм HEPES, pH 7.5, $150 \mathrm{~mm} \mathrm{NaCl}, 1 \mathrm{~mm}$ ethylenediaminetetraacetic acid (EDTA) $1 \%$ Triton X-100, 1X protease inhibitor mixture (Roche Applied Science) and 10 $\mu \mathrm{M}$ Benzyloxycarbonyl-Val-Ala-Asp (OMe) fluoromethylketone (zVAD-FMK, ENZO Life Sciences). The cell lysates were determined by the Bradford assay (BioRad). Samples were used for sodium dodecyl sulfate polyacrylamide gel electrophoresis and western blot analyses by probing with different antibodies: monoclonal antibodies to caspase-9 (1:1000, M054-3, clone 5B4) and caspase-7 (1:1000 M053-3, clone 4G2) from Medical \& Biological Laboratories; polyclonal rabbit antibodies to $\operatorname{Atg} 7(1: 1000,2631 \mathrm{~S})$, cleaved caspase- 9 (1:1000, $52873 \mathrm{~s})$, caspase-3 (1:1000, $9665 \mathrm{~s})$; cleaved caspase-3 (1:1000, $9501 \mathrm{~s})$, caspase-6 (1:1000, $9762 \mathrm{~s}), \mathrm{Mcl}-$ 1 (1:1000, $5453 \mathrm{~s})$, Bcl-2 (1:1000, $4223 \mathrm{~s})$, Bcl-xL (1:1000, $2762 \mathrm{~s})$, Bak (1:1000, 12105 s), Bax (1:1000, 2772 s), LC3 (1:1000, 4108 s) from Cell Signaling Technology and monoclonal antibody to $\beta$-Actin (1:50,000, sc-47778, clone C4) from Santa Cruz Biotechnology. The blots were them incubated with HRP-conjugated goat anti-mouse IgG1 (1:50,000, 1070-05, Southern Biotech) or HRP-conjugated goat anti-Rabbit IgG (1:50,000, ab6721, Abcam) and developed using SuperSignal West Dura Extended Duration Substrate (ThermoFisher).

Quantification of HIV-1 mRNA and DNA. HIV-1 mRNA was measured by RTPCR similar to the described protocol ${ }^{67}$. LTR-gag was amplified with forward primer (LTR-GAG-AF), 5'-GATCTCTCGACGCAGGACTC-3' and reverse primer (LTR-GAG-AR), 5'-CGCTTAATACCGACGCTCTC-3', and detected with the LTR-gag probe, 5HEX/CCAGTCGCC/ZEN/GCCCCTCGCCTC/3IABkFQ. HIV-1 pol-1 was amplified with POL-1 forward primer (POL-1-AF), 5'-AGCAGGAAGA TGGCCAGTAA- $3^{\prime}$ and reverse primer (POL-1-AR), 5'-GGATTGTAGGGAATG CCAAA- $3^{\prime}$, and detected with the pol-1 probe FAM/CCCACCAAC/ZEN/ARGC RGCCTTAACYG/3IABKFQ in iTaq Universal Probes Supermix (Bio-Rad). The reaction was carried out by iTaq Universal Probes Supermix (Bio-Rad) with a QuantStudio 5 Real-Time PCR System and analyzed with the QuantStudio Design and Analysis Software (Applied Biosystem). Cycle threshold (Ct) values were calibrated using standard curve generated with the standard samples with known amounts of viral copies.

Spleen cells were isolated and red blood cells were lysed with ammonium chloride lysing buffer ( $0.15 \mathrm{~m} \mathrm{NH} 4 \mathrm{Cl}, 10 \mathrm{~mm}$ KHCO3, $0.1 \mathrm{~mm}$ EDTA). Bone marrow cells were collected from femur and tibia. The cells were used for mRNA preparation with MagMAX-96 for Microarrays Total RNA Isolation Kit (ThermoFisher Scientific). Tissues $(50 \mathrm{mg})$ were homogenized with Precellys Lysing Kit (Cayman Chemical). mRNA was extracted and converted to cDNA using the SuperScript VILO cDNA Synthesis Kit (Thermo Fisher Scientific), followed by real-time PCR for Pol-1 and LTR-gag as above. Quantity of viral DNA was performed by real-time PCR of genomic DNA from the cells with the described primers as described ${ }^{68}$ : forward primer, $5^{\prime}$-GGTCTCTCTGGTTAGAC CAGAT $-3^{\prime}$ and reverse primer, AGATTTTCCACACTG and probe $5^{\prime}$-6FAMAGT AGTGTGTGCCCGTCTGTT-TAMRA-3') for amplification of an HIV-1 LTR sequence. 
Generation of humanized mice for HIV-1 infection and cure studies. NSGSGM3 mice (stock no: 013062, The Jackson Laboratory) were maintained on a 12hour light/dark cycle with the temperature $\left(22^{\circ} \mathrm{C}\right)$ and humanity $(40-60 \%)$ controlled environment in the specific-pathogen-free barrier animal facility at the Houston Methodist Research Institute. Newborn male and female mice were injected intrahepatically with $\mathrm{CD} 34^{+}$human stem cells $\left(5 \times 10^{4} /\right.$ mouse; AllCells LLC). Three months later, reconstitution of human immune cells in mouse peripheral blood was determined by flow cytometry. Both male and female mice were used for the experiments. HIV-1-infection and cure experiments were performed in Biosafety Level 2 facilities in the Houston Methodist Research Institute. These human $\mathrm{CD} 34^{+}$cell-reconstituted mice (Hu-HSC mice) were then injected intraperitoneally with HIV-1 AD8 (1000 pfu/mouse). Seven days later, peripheral blood was collected and RNA was extracted using the MagMAX-96 Blood RNA Isolation Kit (Thermo Fisher Scientific). RNA was converted to cDNA using the SuperScript VILO cDNA Synthesis Kit (Thermo Fisher Scientific), followed by real-time PCR for LTR-gag and Pol-1 as above. Experiments were performed according to federal and institutional guidelines and with the approval of the Institutional Animal Care and Use Committee of the Houston Methodist Research Institute.

A total of eight sets of experiments were performed to establish HIV-1 infections and treatments using HSC-Hu mice, including three sets of experiments to test the reconstitution of NSG-SGM3 mice with human $\mathrm{CD}_{3} 4^{+}$stem cells and the establishment of HIV-1 infections in these mice, two sets of experiments to determine the dose of drugs that could be safely used in C57BL/6 mice and NSGSGM3-derived HSC-Hu mice, one set of experiments in Supplementary Fig. 5c-g to test the SECH procedure after initial ART treatments, one set of experiments with SECH treatments in Figs. 3-4 and Supplementary Figs. 4-7, and one set of SECH treatments with or without JQ1 in Fig. 5 and Supplementary Fig. 8. For SECH treatments, raltegravir (20 mg/kg b.w.), BMS-663068 (20 mg/kg b.w., Adooq Bioscience), IDB (2.5 mg/kg b.w.), ABT-263 (50 mg/kg b.w.), and SAR405 (50 mg/ $\mathrm{kg}$ b.w.) with or without JQ1 $(25 \mathrm{mg} / \mathrm{kg}$ b.w.) were formulated in the solvent containing 10\% ethanol, 30\% polyethylene glycol 400 (Sigma), and 60\% Phosal 50 PG (Fisher Scientific), and administered by oral gavage once every 2 days. Raltegravir and BMS-663068 (20 mg/kg b.w.) alone were also administered on the alternate days. For the ART control group, raltegravir and BMS-663068 $(20 \mathrm{mg} / \mathrm{kg}$ b.w.) were given daily. In addition, tablets containing non-steroid antiinflammatory carprofen ${ }^{69}(2 \mathrm{mg}$ in each $5 \mathrm{~g}$ tablet, Bio-Serv) were supplied together with regular diet pellets to mice. During treatments, mice were monitored daily for body weight, food consumption, and mobilities. At the end of experiment, histological analysis by hematoxylin and eosin staining was carried out in the major vital organs (brain, liver, lung, and kidney).

Peripheral blood was collected at different intervals to detect HIV-1 mRNA by RT-PCR. After treatments, spleen and bone marrow were collected for analyses by RT-PCR, virus outgrowth assay and intracellular staining for HIV-1 p24. Some mice were kept for an additional 2 months with no treatments. Virus clearance was determined in the spleen, bone marrow by RT-PCR, TZA assay, and p24 intracellular staining. RT-PCR was also performed to detect HIV-1 mRNA in the lung, liver, and kidney for some mice.

TZA assay. TZM-bl cells ${ }^{70}$ obtained from the NIH AIDS Reagent Program were cultured in 96 -well plates $(60,000$ cells/well) for 24 hours. TZA assay was performed similar to described procedures ${ }^{50}$. Spleen and bone marrow cells $\left(5 \times 10^{6} \%\right.$ sample) from Hu-HSC mice were stimulated with anti-CD3- and anti-D28Dynalbeads for $48 \mathrm{~h}$, followed by co-cultured with TZM-bl cells for another $48 \mathrm{~h}$ in the presence of $5 \mu \mathrm{g} / \mathrm{ml}$ PHA, $0.1 \mu \mathrm{g} / \mathrm{ml}$ LPS and $100 \mathrm{~nm} \mathrm{CpG}$. Beta-galactosidase activity was determined using the Beta-Glo Assay System (Promega). This virus outgrowth assay can detect between 1 and 400 pfu of HIV-1 in a linear fashion, and the virus titers in the samples were calculated based on HIV-1 standard titration.

Hu-HSC mouse-based virus outgrowth assay in vivo (hmVOA). Spleen or bone marrow cells $\left(5 \times 10^{6} /\right.$ sample $)$ from HIV-1-infected Hu-HSC mice treated by SECH or ART were transferred into uninfected recipient Hu-HSC mice intravenously similar to previously described procedures ${ }^{54}$. HIV-1 in the peripheral blood of recipient mice was determined 4 weeks later by RT-PCR. PBMCs from HIV-1infected patients $\left(3 \times 10^{6} / \mathrm{sample}\right)$ with or without SECH treatments in vitro were also transferred into Hu-HSC mice intravenously. HIV-1 in the mouse peripheral blood was determined by RT-PCR.

Treatment of PBMCs from HIV-1-infected patients. PBMCs from HIV-1 patients were resuspended in RPMI complete medium containing and $0.3 \mathrm{ng} / \mathrm{ml} \mathrm{IL-2}$ and 50 $\mathrm{ng} / \mathrm{ml} \mathrm{M}$-CSF and cultured with $0.2 \mu \mathrm{M}$ BMS-626529, $0.2 \mu \mathrm{M}$ raltegravir, $25 \mathrm{nM}$ IDB, $20 \mathrm{~nm}$ ABT-263, $0.1 \mu \mathrm{m}$ SAR405, and $0.25 \mu \mathrm{M}$ JQ1 for 2 days as one cycle of treatments. The cells were then washed and cultures in the same medium for next cycle of culture. After seven cycles of culture, RNA was prepared from the cells for RT-PCR analyses of HIV-1. For hmVOA, the cells were incubated with biotin-conjugated anti$\mathrm{CD} 8$ and BioMag streptavidin beads (Sigma) to deplete $\mathrm{CD}^{+} \mathrm{T}$ cells. The cells $(3 \times$ $10^{6}$ ) were then adoptively transfer into uninfected Hu-HSC mice intravenously for hmVOA as above. Experiments with ART-naive patients were performed according to federal and institutional guidelines, with written informed consents and the approval of the Institutional Review Boards of University of Texas Health Science Center at Houston and Houston Methodist Research Institute. Experiments with deidentified samples from ART-treated patients were performed according to federal and institutional guidelines with the approval of the Institutional Review Board of the Houston Methodist Research Institute.

Statistical analyses. GraphPad Prism 8 was used for statistical analyses. Data were presented as the mean \pm SD and $p$ values were determined by two-tailed Student's test. Mann-Whitney test was also used for analyzing humanized mice and patient PBMCs. Significant statistical differences $\left({ }^{*} p<0.05\right.$ or $\left.{ }^{* *} p<0.01\right)$ are indicated.

Reporting summary. Further information on research design is available in the Nature Research Reporting Summary linked to this article.

\section{Data availability}

Source data are provided with this paper. All the other data supporting the findings of this study are available within the article and are available from the corresponding author.

Received: 12 January 2020; Accepted: 15 July 2020;

Published online: 13 August 2020

\section{References}

1. Barre-Sinoussi, F. et al. Isolation of a T-lymphotropic retrovirus from a patient at risk for acquired immune deficiency syndrome (AIDS). Science $\mathbf{2 2 0}$ 868-871 (1983)

2. Deeks, S. G. et al. J. International AIDS Society global scientific strategy: towards an HIV cure 2016. Nat. Med. 22, 839-850 (2016).

3. Simon, V. \& Ho, D. D. HIV-1 dynamics in vivo: implications for therapy. Nat Rev. Microbiol. 1, 181-190 (2003).

4. Abrahams, M. R. et al. The replication-competent HIV-1 latent reservoir is primarily established near the time of therapy initiation. Sci. Transl. Med. 11, eaaw5589 (2019).

5. Whitney, J. B. et al. Rapid seeding of the viral reservoir prior to SIV viraemia in rhesus monkeys. Nature 512, 74-77 (2014).

6. Chun, T. W. et al. Presence of an inducible HIV-1 latent reservoir during highly active antiretroviral therapy. Proc. Natl Acad. Sci. USA 94, 13193-13197 (1997).

7. Finzi, D. et al. Identification of a reservoir for HIV-1 in patients on highly active antiretroviral therapy. Science 278, 1295-1300 (1997).

8. Wong, J. K. et al. Recovery of replication-competent HIV despite prolonged suppression of plasma viremia. Science 278, 1291-1295 (1997).

9. Richman, D. D. et al. The challenge of finding a cure for HIV infection. Science 323, 1304-1307 (2009).

10. Gupta, R. K. et al. HIV-1 remission following CCR5Delta32/Delta32 haematopoietic stem-cell transplantation. Nature 568, 244-248 (2019).

11. Hutter, G. et al. Long-term control of HIV by CCR5 Delta32/Delta32 stem-cell transplantation. N. Engl. J. Med. 360, 692-698 (2009).

12. Margolis, D. M., Garcia, J. V., Hazuda, D. J. \& Haynes, B. F. Latency reversal and viral clearance to cure HIV-1. Science 353, aaf6517 (2016).

13. Rasmussen, T. A. \& Lewin, S. R. Shocking HIV out of hiding: where are we with clinical trials of latency reversing agents? Curr. Opin. HIV AIDS 11, 394-401 (2016)

14. Dash, P. K. et al. Sequential LASER ART and CRISPR treatments eliminate HIV 1 in a subset of infected humanized mice. Nat. Commun. 10, 2753 (2019).

15. Bruner, K. M. et al. A quantitative approach for measuring the reservoir of latent HIV-1 proviruses. Nature 566, 120-125 (2019).

16. Sakai, K., Dimas, J. \& Lenardo, M. J. The Vif and Vpr accessory proteins independently cause HIV-1-induced T cell cytopathicity and cell cycle arrest. Proc. Natl Acad. Sci. USA 103, 3369-3374 (2006).

17. Gandhi, R. T. et al. HIV-1 directly kills CD4+ T cells by a Fas-independent mechanism. J. Exp. Med. 187, 1113-1122 (1998).

18. Muro-Cacho, C. A., Pantaleo, G. \& Fauci, A. S. Analysis of apoptosis in lymph nodes of HIV-infected persons. Intensity of apoptosis correlates with the general state of activation of the lymphoid tissue and not with stage of disease or viral burden. J. Immunol. 154, 5555-5566 (1995).

19. Finkel, T. H. et al. Apoptosis occurs predominantly in bystander cells and not in productively infected cells of HIV- and SIV-infected lymph nodes. Nat. Med. 1, 129-134 (1995).

20. Gougeon, M. L. et al. Programmed cell death in peripheral lymphocytes from HIV-infected persons: increased susceptibility to apoptosis of CD4 and CD8 $\mathrm{T}$ cells correlates with lymphocyte activation and with disease progression. J. Immunol. 156, 3509-3520 (1996). 
21. Jekle, A. et al. In vivo evolution of human immunodeficiency virus type 1 toward increased pathogenicity through CXCR4-mediated killing of uninfected CD4 T cells. J. Virol. 77, 5846-5854 (2003).

22. Grivel, J. C., Malkevitch, N. \& Margolis, L. Human immunodeficiency virus type 1 induces apoptosis in $\mathrm{CD} 4(+)$ but not in $\mathrm{CD} 8(+) \mathrm{T}$ cells in ex vivoinfected human lymphoid tissue. J. Virol. 74, 8077-8084 (2000).

23. Cooper, A. et al. HIV-1 causes CD4 cell death through DNA-dependent protein kinase during viral integration. Nature 498, 376-379 (2013).

24. Doitsh, G. et al. Cell death by pyroptosis drives CD4 T-cell depletion in HIV-1 infection. Nature 505, 509-514 (2014).

25. Chen, M. et al. Essential role for autophagy in the maintenance of immunological memory against influenza infection. Nat. Med. 20, 503-510 (2014).

26. $\mathrm{Xu}, \mathrm{X}$. et al. Autophagy is essential for effector $\mathrm{CD} 8(+) \mathrm{T}$ cell survival and memory formation. Nat. Immunol. 15, 1152-1161 (2014).

27. Puleston, D. J. et al. Autophagy is a critical regulator of memory CD8(+) T cell formation. Elife 3, e03706 (2014).

28. Murera, D. et al. CD4 T cell autophagy is integral to memory maintenance. Sci. Rep. 8, 5951 (2018).

29. Saleh, S. et al. CCR7 ligands CCL19 and CCL21 increase permissiveness of resting memory CD4+ T cells to HIV-1 infection: a novel model of HIV-1 latency. Blood 110, 4161-4164 (2007).

30. Adachi, A. et al. Production of acquired immunodeficiency syndromeassociated retrovirus in human and nonhuman cells transfected with an infectious molecular clone. J. Virol. 59, 284-291 (1986).

31. Jiang, G. et al. Reactivation of HIV latency by a newly modified Ingenol derivative via protein kinase Cdelta-NF-kappaB signaling. AIDS 28, 1555-1566 (2014).

32. Tanida, I., Tanida-Miyake, E., Ueno, T. \& Kominami, E. The human homolog of Saccharomyces cerevisiae Apg7p is a Protein-activating enzyme for multiple substrates including human Apg12p, GATE-16, GABARAP, and MAP-LC3. J. Biol. Chem. 276, 1701-1706 (2001)

33. Ronan, B. et al. A highly potent and selective Vps34 inhibitor alters vesicle trafficking and autophagy. Nat. Chem. Biol. 10, 1013-1019 (2014).

34. Mauthe, M. et al. Chloroquine inhibits autophagic flux by decreasing autophagosome-lysosome fusion. Autophagy 14, 1435-1455 (2018).

35. Freed, E. O., Englund, G. \& Martin, M. A. Role of the basic domain of human immunodeficiency virus type 1 matrix in macrophage infection. J. Virol. 69, 3949-3954 (1995).

36. Schmidtmayerova, H., Alfano, M., Nuovo, G. \& Bukrinsky, M. Human immunodeficiency virus type $1 \mathrm{~T}$-lymphotropic strains enter macrophages via a CD4- and CXCR4-mediated pathway: replication is restricted at a postentry level. J. Virol. 72, 4633-4642 (1998).

37. Liszewski, M. K., Yu, J. J. \& O’Doherty, U. Detecting HIV-1 integration by repetitive-sampling Alu-gag PCR. Methods 47, 254-260 (2009).

38. Choi, H. J. \& Smithgall, T. E. HIV-1 Nef promotes survival of TF-1 macrophages by inducing Bcl-XL expression in an extracellular signalregulated kinase-dependent manner. J. Biol. Chem. 279, 51688-51696 (2004).

39. Tse, C. et al. ABT-263: a potent and orally bioavailable Bcl-2 family inhibitor. Cancer Res. 68, 3421-3428 (2008).

40. Chavez, L., Calvanese, V. \& Verdin, E. HIV latency is established directly and early in both resting and activated primary CD4 T cells. PLoS Pathog. 11, e1004955 (2015).

41. Jacquin, E. \& Apetoh, L. Cell-intrinsic roles for autophagy in modulating CD4 T cell functions. Front. Immunol. 9, 1023 (2018).

42. Zhu, L. et al. Pharmacokinetic interactions between BMS-626529, the active moiety of the HIV-1 attachment inhibitor prodrug BMS-663068, and ritonavir or ritonavir-boosted atazanavir in healthy subjects. Antimicrob. Agents Chemother. 59, 3816-3822 (2015).

43. Marsden, M. D. \& Zack, J. A. Humanized mouse models for human immunodeficiency virus infection. Annu Rev. Virol. 4, 393-412 (2017).

44. Nettles, R. E. et al. Pharmacodynamics, safety, and pharmacokinetics of BMS663068, an oral HIV-1 attachment inhibitor in HIV-1-infected subjects. J. Infect. Dis. 206, 1002-1011 (2012).

45. Grinsztejn, B. et al. \& Protocol, T. Safety and efficacy of the HIV-1 integrase inhibitor raltegravir (MK-0518) in treatment-experienced patients with multidrug-resistant virus: a phase II randomised controlled trial. Lancet 369, 1261-1269 (2007)

46. Wunderlich, M. et al. AML xenograft efficiency is significantly improved in NOD/SCID-IL2RG mice constitutively expressing human SCF, GM-CSF and IL-3. Leukemia 24, 1785-1788 (2010).

47. Billerbeck, E. et al. Development of human CD4+FoxP3+ regulatory T cells in human stem cell factor-, granulocyte-macrophage colony-stimulating factor-, and interleukin-3-expressing NOD-SCID IL2Rgamma(null) humanized mice. Blood 117, 3076-3086 (2011).

48. Coughlan, A. M. et al. Myeloid engraftment in humanized mice: impact of granulocyte-colony stimulating factor treatment and transgenic mouse strain. Stem Cells Dev. 25, 530-541 (2016).
49. Gupta, P., Sanyal, A. \& Mailliard, R. B. TZA: a novel assay for measuring the latent HIV-1 reservoir. Expert Rev. Mol. Diagn. 17, 1033-1035 (2017).

50. Sanyal, A. et al. Novel assay reveals a large, inducible, replication-competent HIV-1 reservoir in resting CD4(+) T cells. Nat. Med. 23, 885-889 (2017).

51. Bruner, K. M. et al. Defective proviruses rapidly accumulate during acute HIV-1 infection. Nat. Med. 22, 1043-1049 (2016).

52. Gupta, R. K. et al. Evidence for HIV-1 cure after CCR5Delta32/Delta32 allogeneic haemopoietic stem-cell transplantation 30 months post analytical treatment interruption: a case report. Lancet HIV 7, e340-e347 (2020).

53. Schmitt, K. \& Akkina, R. Ultra-sensitive HIV-1 latency viral outgrowth assays using humanized mice. Front Immunol. 9, 344 (2018).

54. Charlins, P. et al. A humanized mouse-based HIV-1 viral outgrowth assay with higher sensitivity than in vitro qVOA in detecting latently infected cells from individuals on ART with undetectable viral loads. Virology 507, 135-139 (2017).

55. Mbonye, U. \& Karn, J. Control of HIV latency by epigenetic and nonepigenetic mechanisms. Curr. HIV Res. 9, 554-567 (2011).

56. Zhu, J. et al. Reactivation of latent HIV-1 by inhibition of BRD4. Cell Rep. 2 , 807-816 (2012).

57. Darcis, G. et al. An in-depth comparison of latency-reversing agent combinations in various in vitro and ex vivo HIV-1 latency models identified bryostatin-1+JQ1 and ingenol-B+JQ1 to potently reactivate viral gene expression. PLoS Pathog. 11, e1005063 (2015).

58. Schlie, $\mathrm{K}$. et al. Survival of effector $\mathrm{CD} 8+\mathrm{T}$ cells during influenza infection is dependent on autophagy. J. Immunol. 194, 4277-4286 (2015).

59. Levine, B. \& Kroemer, G. Biological functions of autophagy genes: a disease perspective. Cell 176, 11-42 (2019).

60. Kyei, G. B. et al. Autophagy pathway intersects with HIV-1 biosynthesis and regulates viral yields in macrophages. J. Cell Biol. 186, 255-268 (2009).

61. Eekels, J. J. et al. Inhibition of HIV-1 replication with stable RNAi-mediated knockdown of autophagy factors. Virol. J. 9, 69 (2012).

62. Steichen, J. M. et al. A generalized HIV vaccine design strategy for priming of broadly neutralizing antibody responses. Science 366, eaax4380 (2019).

63. Saunders, K. O. et al. Targeted selection of HIV-specific antibody mutations by engineering B cell maturation. Science 366, eaay7199 (2019).

64. Mendoza, P. et al. Combination therapy with anti-HIV-1 antibodies maintains viral suppression. Nature 561, 479-484 (2018).

65. Anthony-Gonda, K. et al. Multispecific anti-HIV duoCAR-T cells display broad in vitro antiviral activity and potent in vivo elimination of HIV-infected cells in a humanized mouse model. Sci. Transl. Med. 11, eaav5685 (2019).

66. Herzig, E. et al. Attacking latent HIV with convertibleCAR-T cells, a hghly adaptable killing platform. Cell 179, 880-894 e810 (2019).

67. Noorbazargan, H., Nadji, S. A., Samiee, S. M., Paryan, M. \& MohammadiYeganeh, S. New design, development, and optimization of an in-house quantitative TaqMan Real-time PCR assay for HIV-1 viral load measurement. HIV Clin. Trials 19, 61-68 (2018).

68. Utay, N. S. et al. Timing of antiretroviral therapy initiation determines rectal natural killer cell populations. AIDS Res. Hum. Retroviruses 36, 314-323 (2020).

69. Liles, J. H. \& Flecknell, P. A. The use of non-steroidal anti-inflammatory drugs for the relief of pain in laboratory rodents and rabbits. Lab Anim. 26, 241-255 (1992).

70. Derdeyn, C. A. et al. Sensitivity of human immunodeficiency virus type 1 to the fusion inhibitor T-20 is modulated by coreceptor specificity defined by the V3 loop of gp120. J. Virol. 74, 8358-8367 (2000).

\section{Acknowledgements}

We thank Albert Jang, Srikanth Kodali, Le Kuai, Wayne Marasco, and Jun-Zheng Wang for technical support, and Andrew Rice for discussions. We thank Laurie Minze and Olga Ortiz for administrative support, and the Houston Methodist Research Institute Biorepository for providing patient samples. This study was supported by funding from the NIH (R01AI116644 and R01AI123221 to J.W., R33AI116167 to J.T.K., 5P30AI036211 to R.C.A.), the Cancer Prevention and Research Institute of Texas (RP160384 to J.W. and M.C.), the US Department of Defense (PR140593 to M.C.), and the Houston Methodist Research Institute (to J.W.).

\section{Author contributions}

M.C. and M.L. designed and performed experiments. W.L. performed experiments. T.B. assisted with experiments. J.T.K. gave advice on HIV infections. R.C.A. and E.A.G. obtained patient samples. J.W. conceived and designed the study, performed experiments and wrote the paper.

\section{Competing interests}

The authors declare no competing interests. 


\section{Additional information}

Supplementary information is available for this paper at https://doi.org/10.1038/s41467020-17753-w.

Correspondence and requests for materials should be addressed to J.W.

Peer review information Nature Communications thanks Ravindra Gupta, Christian Munz and the other, anonymous, reviewer(s) for their contribution to the peer review of this work.

Reprints and permission information is available at http://www.nature.com/reprints

Publisher's note Springer Nature remains neutral with regard to jurisdictional claims in published maps and institutional affiliations. (c) (i) Open Access This article is licensed under a Creative Commons Attribution 4.0 International License, which permits use, sharing, adaptation, distribution and reproduction in any medium or format, as long as you give appropriate credit to the original author(s) and the source, provide a link to the Creative Commons license, and indicate if changes were made. The images or other third party material in this article are included in the article's Creative Commons license, unless indicated otherwise in a credit line to the material. If material is not included in the article's Creative Commons license and your intended use is not permitted by statutory regulation or exceeds the permitted use, you will need to obtain permission directly from the copyright holder. To view a copy of this license, visit http://creativecommons.org/ licenses/by/4.0/.

(C) The Author(s) 2020, corrected publication 2020 